FERNANDA DE ALMEIDA SANTOS

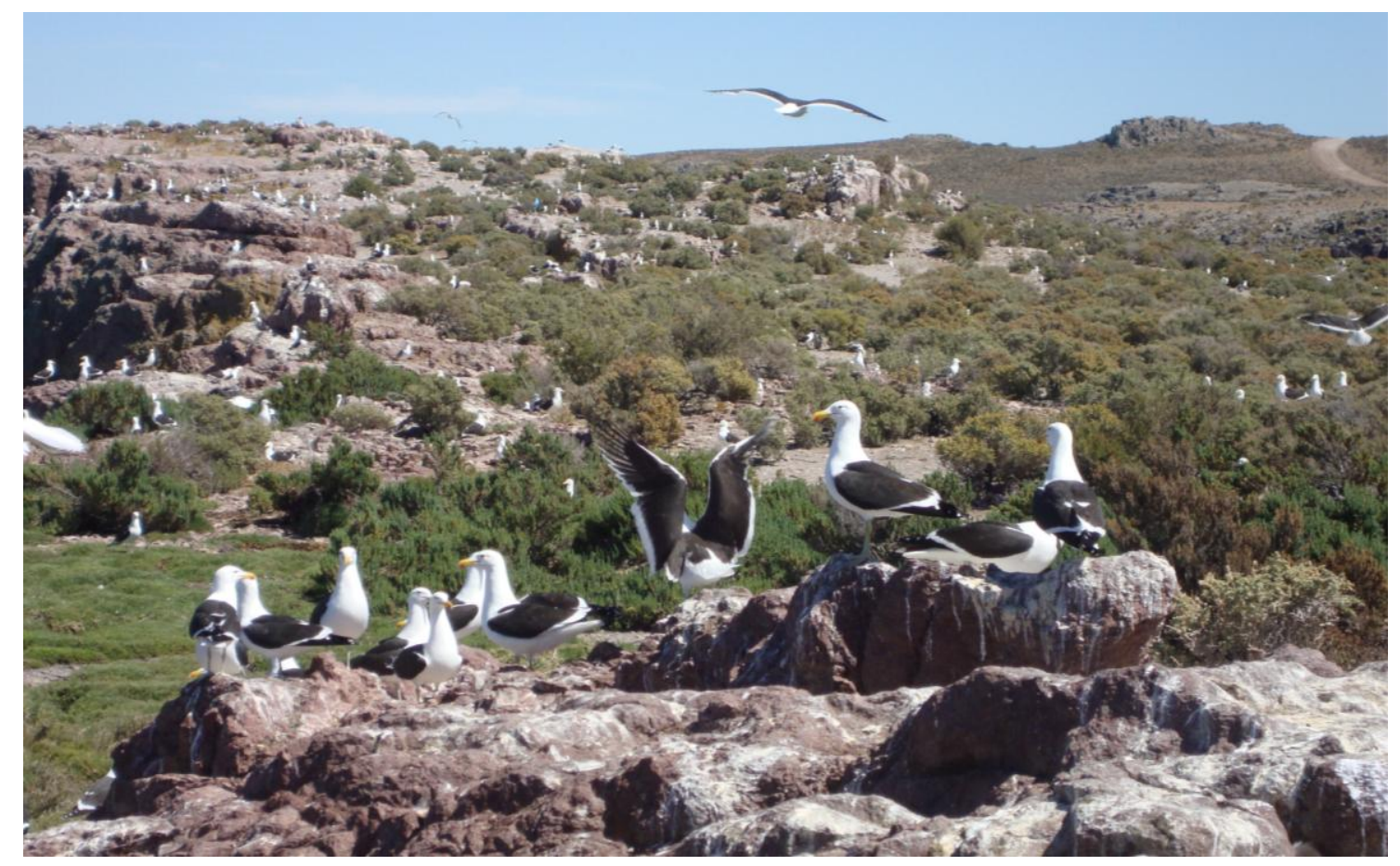

ANÁLISE POPULACIONAL GENÉTICA DE LARUS DOMINICANUS ATRAVÉS DO USO DE MICROSSATÉLITES

SÃO PAULO 
FERNANDA DE ALMEIDA SANTOS

\section{ANÁliSE POPULACIONAL GENÉTICA DE LARUS DOMINICANUS ATRAVÉS DO USO DE MICROSSATÉLITES}

Dissertação apresentada ao Instituto de Biociências da Universidade de São Paulo, para obtenção do título de Mestre em Ciências, na Área de Genética e Biologia Evolutiva.

Orientador: Prof. Dr. João Stenghel Morgante

São Paulo

2011 
À minha avó e aos meus pais, por me ensinarem as primeiras letras e me incentivarem a buscar respostas para os meus muitos porquês. 


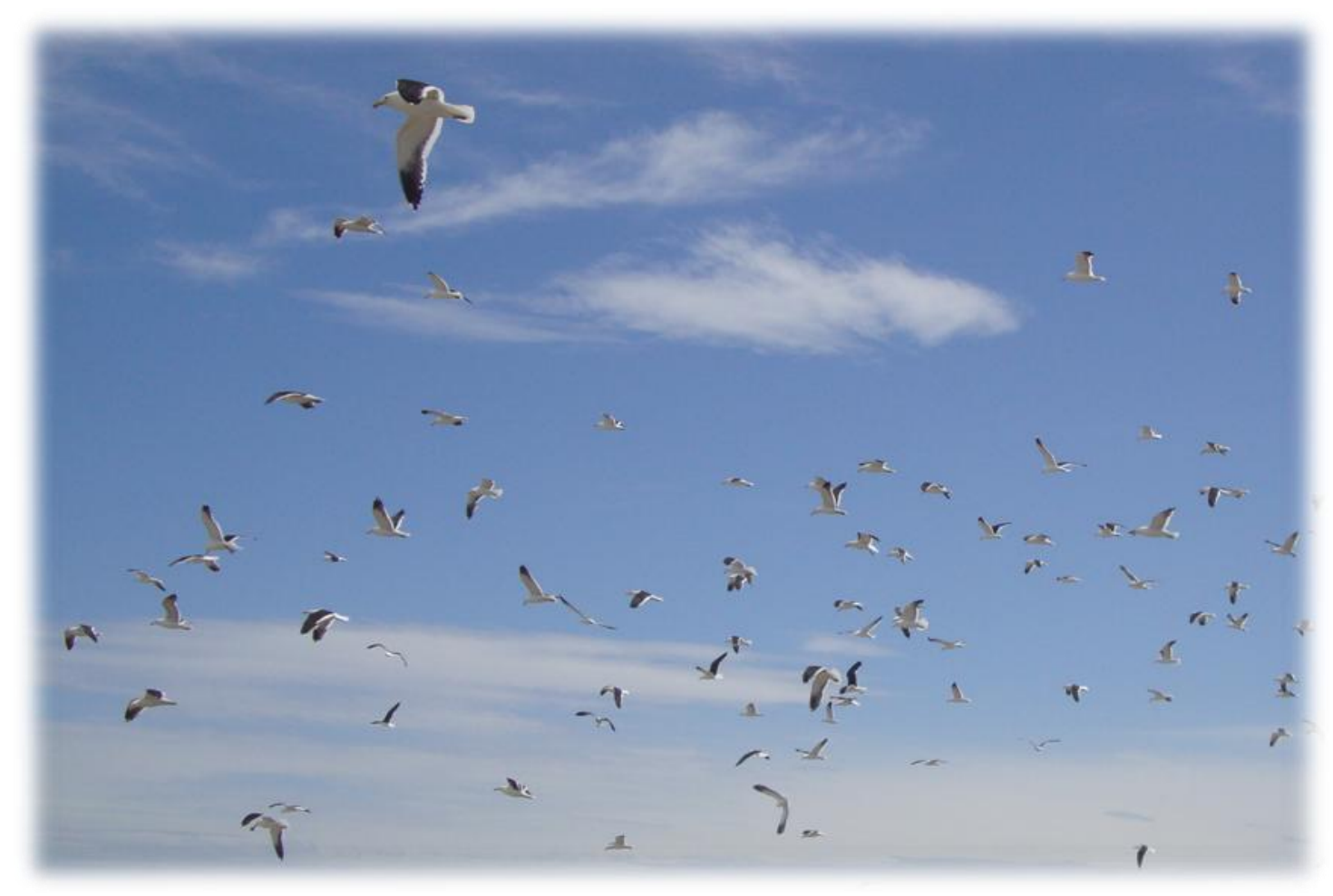

"A maior parte das gaivotas não se querem incomodar a aprender mais do que os rudimentos do voo, como ir da costa à comida e voltar. Para a maior parte das gaivotas, $\mathrm{o}$ que importa não é saber voar, mas comer, como de resto a maior parte dos seres humanos. Porém, para esta gaivota, o mais importante não era comer, mas sim voar, saber mais, conhecer mais 'alto'."

(Trecho do livro Fernão Capelo Gaivota, de Richard Bach) 


\section{AGRADECIMENTOS}

Às vezes algumas coisas simplesmente acontecem em nossas vidas. Outras vezes algumas pessoas fazem com que elas aconteçam no melhor momento e da melhor maneira. Este trabalho é o fruto do incentivo, do apoio e da compreensão de muitas pessoas que o fizeram acontecer.

Ao meu orientador, Professor João, pela sabedoria de me impulsionar ao início, por me aceitar independente de todas as dificuldades, por cada abraço de carinho, sempre tão receptivo.

À minha co-orientadora, Gisele Dantas, por me fazer voar mais alto, por me ensinar a ver através, por cada fim de semana, cada madrugada, por despertar em mim o questionamento de um pesquisador.

A todos os colegas de laboratório, pelo companheirismo, por dividirmos placas, géis a risadas. Em especial, às amigas Gabriela, Márcia e Kelly, por tanto ajudarem com o nosso falecido ABI quando eu não podia estar presente.

À amiga e companheira de congressos Flávia Presti, que me ajudou a desvendar os mistérios dos microssatélites. À Adriana Marques, pela ajuda na bancada com as tentativas de seqüenciamento.

A cada um dos meus amigos, por entenderem meus momentos de ausência, meus telefonemas corridos e respeitarem este espaço de tempo que precisei para o amadurecimento e conclusão deste trabalho. Em especial, ao meu amigo Ivan, por ter me trazido até as gaivotas e por me ensinar a ser uma pessoa menos estressada.

Aos meus colegas de trabalho, que tanto já ouviram sobre esta dissertação, que já sabem sobre as gaivotas mesmo à distância, que me deram suporte quando eu tantas vezes precisei me ausentar.

Ao meu marido, que me fez rir quando muitas vezes eu queria chorar, que dividiu comigo meus momentos de desespero com prazos, de descobertas com dados, mesmo sem ter um nada de biólogo. 
À minha irmã, por estar sempre ao meu lado, pelas conversas que sempre me fizeram bem, por me fazer ver que a vida é curta demais pra ser tão levada a sério, por me ensinar a rir dos meus próprios erros.

Aos meus pais, por alimentarem desde o início a minha vontade de saber, por me darem asas pra chegar até aqui, por respeitarem minhas escolhas e estarem sempre prontos para aplaudir ou amparar, pelas pequenas e grandes atitudes que tornaram meu caminho mais tênue.

Aos colaboradores, que ajudaram com a coleta das amostras, Fausto Campos, Professor Dr. Joaquim Olinto Branco, Professor Dr. Martin Sander, Dra. Juliana Vianna, Professor Peter Ryan e à equipe do Professor Dr. Esteban Frere.

À Fundação de Amparo à Pesquisa de São Paulo (FAPESP) e ao Conselho Nacional de Desenvolvimento Científico e Técnológico (CNPq) pelo amparo financeiro. À Coordenação de Aperfeiçoamento de Pessoal de Nível Superior (CAPES), pela bolsa de pesquisa nos meses iniciais deste trabalho.

A este projeto em si, que me fez descobrir que acima do meu carinho pelas gaivotas e do meu gosto pela genética, está a satisfação em aprender. Este projeto me fez ver que independente de quando ou qual será o próximo passo, estudar será um projeto para toda a vida. 


\section{ÍNDICE}

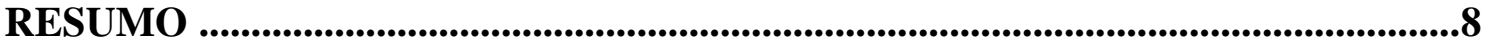

INTRODUÇÃ

MATERIAL E MÉTODOS .....................................................................................12

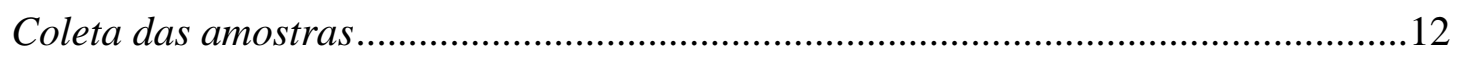

Extração do DNA e amplificação dos microssatélites.................................................16

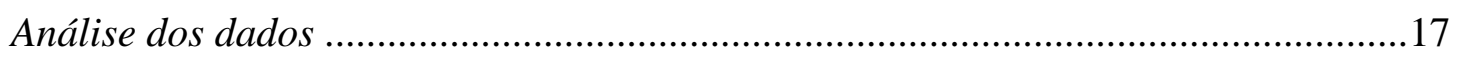

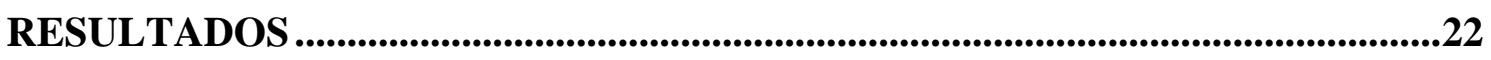

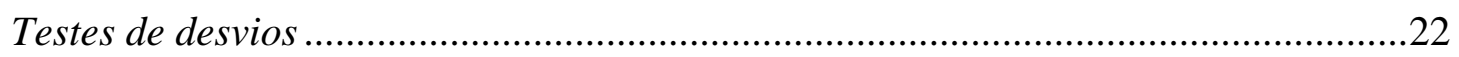

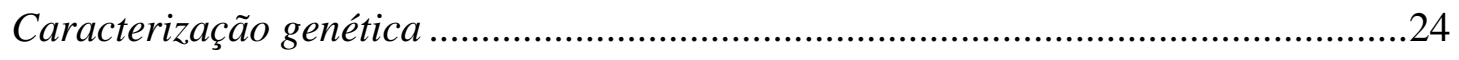

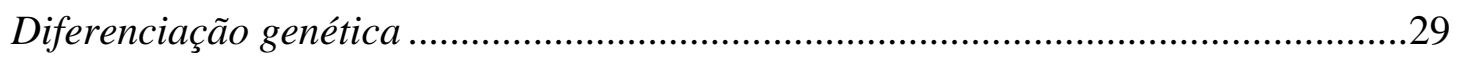

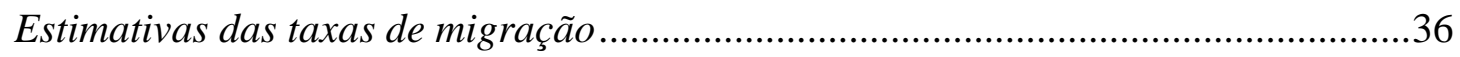

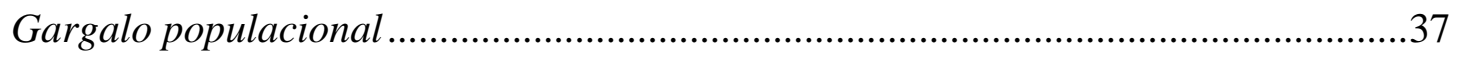

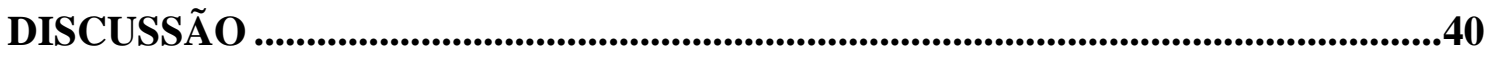

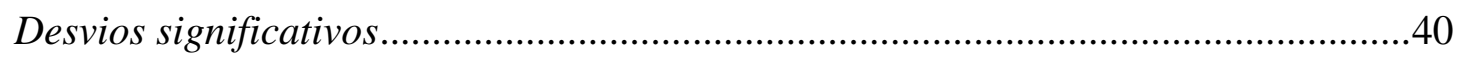

Variabilidade genética, estrutura populacional e fluxo gênico...................................41

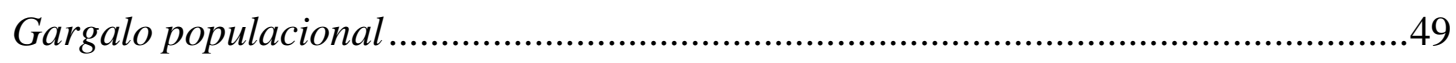

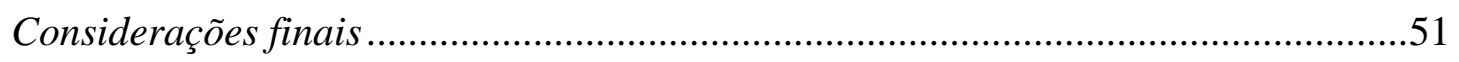




\section{RESUMO}

As alterações que a ação antrópica vem causando nos ambientes costeiros tem provocado impactos sobre as espécies a eles associadas. Larus dominicanus é uma espécie de ave marinha amplamente distribuída ao longo do Hemisfério Sul. Por possuir

um hábito alimentar generalista, os resíduos da ação antrópica tem beneficiado a espécie, que, assim como outras gaivotas, vem apresentando um crescimento demográfico acelerado.

O presente estudo, através do uso de marcadores de microssatélites, mostra que, apesar disso, a espécie possui uma baixa variabilidade genética, com fraca estruturação populacional, que provavelmente são o reflexo da origem recente da espécie e de uma diferenciação recente entre as populações. Múltiplas forças atuam para determinar a estruturação populacional, sendo elas o isolamento por distância, as barreiras físicas e a filopatria. Os sinais de gargalo populacional encontrados em algumas das colônias levantam a possibilidade de efeitos fundadores por colonização recente nas colônias mais ao norte da costa brasileira e redução populacional nas colônias da Argentina e da Antártica como consequiência da última glaciação.

Estes dados chamam a atenção para a necessidade de considerar as informações genéticas para a implantação de planos de manejo. Uma vez que a diferenciação entre as populações é recente, a variabilidade dentro de cada uma delas deve ser mantida. O controle populacional da espécie através de métodos diretos deve ser também acompanhado por planos de manejo ambiental, visando reduzir ou eliminar as condições que propiciam o crescimento desequilibrado dos gaivotões. 


\section{INTRODUÇÃO}

A crescente ocupação humana das áreas costeiras tem resultado em mudanças físicas, químicas e biológicas, que impactam direta e indiretamente as espécies que a elas estão associadas, entre as quais, uma ampla diversidade de aves marinhas. A ação antrópica pode levar ao aumento da mortalidade destas espécies, redução do sucesso reprodutivo e degradação das áreas de nidificação (Schreiber \& Burger, 2000). A destruição ou descaracterização dos habitats, a exploração excessiva de recursos para consumo, a introdução de novas espécies e o turismo desordenado provocam o desequilíbrio das populações (Amaral \& Jablonski, 2005).

Larus dominicanus (família Laridae), popularmente conhecido como gaivotão, distribui-se amplamente no Hemisfério Sul, ocorrendo na América do Sul, no sul da África, Austrália, Nova Zelândia, nas ilhas sub-Antárticas e na Península Antártica (delHoyo et al., 1996; Higgins \& Davis, 1996). No Brasil, essa espécie ocorre do Rio de Janeiro ao Rio Grande do Sul (Sick, 1997). Seu hábito alimentar generalista (Murphy, 1936; Humphrey et al., 1970; Brooke \& Cooper, 1979; Stahl \& Mougin, 1986; Steele, 1992), permite que se alimente de fontes artificiais, resultantes de atividades humanas, como depósitos de lixo, detritos produzidos em matadouros ou nas atividades pesqueiras (Yorio et al., 1998). Além disso, essa espécie apresenta flexibilidade na escolha dos sítios para nidificar, podendo nidificar em locais abertos ou cobertos por vegetação (Borboroglu \& Yorio, 2004).

Fordham \& Cormarck (1970) mostraram que há uma associação entre a disponibilidade de fontes artificiais de alimentação e o decréscimo ou incremento populacional de L. dominicanus. O hábito alimentar da espécie faz com que ela se beneficie das fontes artificiais disponíveis, tendo como conseqüência um aumento 
demográfico. Da mesma forma, a expansão populacional tem sido observada em outras espécies de grandes gaivotas de diversas partes do hemisfério sul (Fordham 1970, Crawford et al. 1982, Blakers et al. 1984, Powlesland \& Robertson 1987, Steele \& Hockey, 1990, Favero \& Silva 1991 apud Yorio et al., 1998), Este crescimento populacional acelerado tem provocado o declínio de outras aves marinhas (Anderson \& Devlin, 1999), em vista da competição interespecífica e da predação de filhotes de outras espécies por L. dominicanus. Os gaivotões já foram observados predando ovos e filhotes de biguás (Punta \& Herrera, 1995; Yorio \& Quintana, 1996), trinta-réis (Yorio \& Quintana, 1996), pinguim de Magalhães (Boswall, 1973; Gochfeld, 1980; Frere et al., 1992; Yorio \& Boersma, 1994) e Petrel Gigante (Yorio et al., 1998).

Os efeitos do crescimento populacional de L. dominicanus sobre animais da costa não têm sido enfrentados somente por aves marinhas (Yorio et al., 1998). Thomas (1988) observou, pela primeira vez, gaivotões alimentando-se de tecido e de camada hipodérmica de baleias franca (Eubalaena australis) vivas, em reprodução, no Golfo de San Jose, Argentina. O mesmo foi observado por Rowntree et al. (1998), na Península Valdés, Argentina. Essa interação tem prejudicado as baleias, que dependem de suas reservas energéticas devido à escassez de alimento nesses locais. Tem ocorrido um aumento no número de baleias com lesões e uma alteração na distribuição espacial das baleias em reprodução (Thomas, 1988; Rowntree et al., 1998)

Uma vez que o crescimento populacional de L. dominicanus está fortemente associado à ocupação desordenada da costa e às ações antrópicas, é de extrema importância o estudo de planos de manejo que permitam restabelecer o equilíbrio das populações. Os genes são, ao mesmo tempo, os produtos e os sujeitos de processos evolutivos que ocorrem ao longo da história das populações, assim, estudos de evolução 
e variação genética são essenciais para o desenvolvimento de práticas em biologia da conservação (Loeschcke et al., 1994). Entender a biologia e a história evolutiva da espécie é o ponto de partida para a elaboração e estruturação de futuras medidas.

Os grupos de indivíduos com semelhanças entre si, dentro de uma mesma espécie, constituem populações. O conceito de população é amplamente explorado na literatura e apresenta variações conforme o paradigma em questão. Neste trabalho, as populações serão abordadas sob o paradigma biológico evolutivo, a força de coesão entre os indivíduos é determinada pelas interações reprodutivas. Sob esta visão, uma população corresponde a um grupo de indivíduos da mesma espécie, vivendo próximo o suficiente, de tal forma que qualquer membro do grupo tem o mesmo potencial de se reproduzir com qualquer outro membro deste mesmo grupo (Waples \& Gaggioti, 2006).

Desde o início do século XX, com as idéias de Wrigth, os geneticistas buscam desenvolver e aprimorar métodos e modelos de estudo das populações naturais. Este estudo só se torna possível através da elaboração de modelos. Modelos não são fiéis à realidade, mas viabilizam o estudo de populações reais, permitindo que sejam feitas estimativas sobre parâmetros como a taxa de fluxo gênico, o tamanho efetivo e a conectividade entre as populações (Hamilton, 2009).

O estudo genético de populações naturais depende da disponibilidade de marcadores moleculares neutros e polimórficos (Schlötterer \& Pemberton, 1994). A neutralidade, a grande variabilidade e a ampla distribuição dos microssatélites fazem com que eles sejam um dos mais eficientes sistemas de marcadores em genética de populações, sua alta taxa de mutação permite recuperar informações recentes das populações, viabilizando o estudo de fluxo gênico, tamanho populacional efetivo, processos de dispersão e migração e relações de parentesco (Kumar \& Fladung, 2004; Ellegren, 2004). 
Microssatélites são uma classe de marcadores de DNA, identificados no genoma de eucariotos pela presença de curtas seqüências repetitivas ( 2 a 6 pares de bases [pb]), podem ocorrer também em procariotos, porém, em menor freqüência (Hoelzel \& Hoelzel, 1998; Kumar \& Fladung, 2004). A freqüência das unidades repetitivas depende do tamanho e da composição do genoma do indivíduo, da variabilidade (diversidade de alelos) e da taxa de mutação do microssatélite (Kumar \& Fladung, 2004). A mutação no microssatélite está diretamente relacionada ao seu comprimento (Primmer \& Ellegren, 1998; Ellegren, 2004), à presença de seqüências flanqueadoras, à sua localização cromossômica e à composição de bases (Bachtrog et al., 2000), além da idade e do sexo do indivíduo (Primmer \& Ellegren, 1998).

Dentro deste contexto e utilizando como marcadores moleculares os microssatélites, este trabalho se propõe a analisar a espécie $L$. dominicanus com os objetivos de: 1) analisar a distribuição da variabilidade genética entre as e dentro das populações do Brasil, do Chile, da Argentina, da Antártica e da ilha Marion (Subantártica); 2) estimar a estrutura populacional e o fluxo gênico recente e ao longo do tempo entre estas populações; 3) verificar a ocorrência de gargalo populacional na espécie ou em uma das populações.

\section{MATERIAL E MÉTODOS}

\section{Coleta das amostras}

Durante as estações reprodutivas de 2001 a 2009, foram coletadas amostras de $L$. dominicanus em nove ilhas da costa brasileira, duas ilhas argentinas, uma ilha chilena, uma ilha da Península Antártica e uma ilha africana (Fig.1). O número de indivíduos amostrados que foram utilizados neste trabalho está discriminado na Tabela I, separados 
de acordo com o local e o ano de coleta. As coletas foram realizadas pelas equipes do Laboratório de Biologia Evolutiva e Conservação de Vertebrados (LABEC) com a colaboração do pesquisador Fausto Campos (Instituto Florestal de São Paulo), do Professor Dr. Joaquim Olinto Branco (Universidade do Vale do Itajaí - UNIVALI, Santa Catarina, Brasil), do Professor Dr. Martin Sander (Universidade do Vale do Rio dos Sinos - UNISINOS, Rio Grande do Sul, Brasil), da equipe do Professor Dr. Esteban Frere (Universidad Nacional de La Patagonia Austral de Puerto Deseado, Santa Cruz, Argentina), da Dra. Juliana Vianna (Universidad Andres Bello, Santiago, Chile) e do Professor Peter Ryan (Percy Fitzpatrick Ornithological Institute, Universidade de Cape Town, África do Sul).

Aproximadamente $0,2 \mathrm{~mL}$ de sangue foram extraídos da veia braquial dos indivíduos capturados, com seringa de insulina, uma técnica que não causa prejuízo ou morte. O sangue foi conservado em etanol $100 \%$, a uma temperatura de $4{ }^{\circ} \mathrm{C}$. As amostras permaneceram no banco de sangue do LABEC, no Instituto de Biologia da Universidade de São Paulo - IB/USP. 
Tabela I - Número de indivíduos amostrados em cada ilha, com suas respectivas coordenadas geográficas e os anos de coleta.

\begin{tabular}{|c|c|c|c|c|}
\hline Ilha & \multicolumn{2}{|c|}{ Coordenadas Geográficas } & \multirow{2}{*}{$\begin{array}{l}\text { Ano } \\
2002\end{array}$} & \multirow{2}{*}{$\begin{array}{c}\begin{array}{c}\mathbf{N}^{\circ} \text { de } \\
\text { indivíduos }\end{array} \\
12\end{array}$} \\
\hline São Pedro (SP) & $23^{\circ} 03^{\prime \prime} \mathrm{S}$ & $44^{\circ} 35^{\prime \prime} \mathrm{O}$ & & \\
\hline Queimadinha (QUE) & $24^{\circ} 22^{\prime \prime} \mathrm{S}$ & $46^{\circ} 48^{\prime \prime} \mathrm{O}$ & 2003 & 9 \\
\hline \multirow{4}{*}{ Guararitama (GUA) } & \multirow{4}{*}{$24^{\circ} 23^{\prime \prime} \mathrm{S}$} & \multirow{4}{*}{$46^{\circ} 59^{\prime \prime} \mathrm{O}$} & 2001 & 25 \\
\hline & & & 2003 & 22 \\
\hline & & & 2004 & 21 \\
\hline & & & 2005 & 17 \\
\hline Laje da Conceição (CON) & $24^{\circ} 14^{\prime \prime} \mathrm{S}$ & $46^{\circ} 41^{\prime \prime} \mathrm{O}$ & 2003 & 6 \\
\hline \multirow{2}{*}{ Moleques do Sul (MOL) } & \multirow{2}{*}{$27^{\circ} 51^{\prime \prime} \mathrm{S}$} & \multirow{2}{*}{$48^{\circ} 26^{\prime \prime} \mathrm{O}$} & 2002 & 13 \\
\hline & & & \multirow{2}{*}{$\begin{array}{l}2004 \\
2002\end{array}$} & 21 \\
\hline Deserta (DES) & $27^{\circ} 16^{\prime \prime} \mathrm{S}$ & $48^{\circ} 19^{\prime \prime} \mathrm{O}$ & & 14 \\
\hline Itacolomis (ITA) & $26^{\circ} 40^{\prime \prime} \mathrm{S}$ & $48^{\circ} 19^{\prime \prime} \mathrm{O}$ & 2002 & 5 \\
\hline Tambores (TAM) & $26^{\circ} 22^{\prime \prime} \mathrm{S}$ & $48^{\circ} 31^{\prime \prime} 0$ & 2002 & 10 \\
\hline Lobos (LOB) & $28^{\circ} 26^{\prime \prime} \mathrm{S}$ & $48^{\circ} 42^{\prime \prime} \mathrm{O}$ & 2002 & 14 \\
\hline Chiloé (CHI) & $41^{\circ} 51^{\prime \prime} \mathrm{S}$ & $73^{\circ} 49^{\prime \prime} 0$ & 2009 & 7 \\
\hline Quiroga (QUI) & $47^{\circ} 45^{\prime \prime} \mathrm{S}$ & $65^{\circ} 56^{\prime \prime} \mathrm{O}$ & 2009 & 20 \\
\hline Chaffers (CHA) & $47^{\circ} 45^{\prime \prime} \mathrm{S}$ & $65^{\circ} 52^{\prime \prime} \mathrm{O}$ & \multirow{2}{*}{$\begin{array}{c}2009 \\
-\end{array}$} & 21 \\
\hline Marion (MAR) & $46^{\circ} 53^{\prime \prime} \mathrm{S}$ & $37^{\circ} 45^{\prime \prime} \mathrm{L}$ & & 6 \\
\hline Rei George (RG) & $61^{\circ} 50^{\prime \prime} \mathrm{S}$ & $57^{\circ} 30^{\prime \prime} \mathrm{O}$ & $2004 / 2005$ & 16 \\
\hline
\end{tabular}




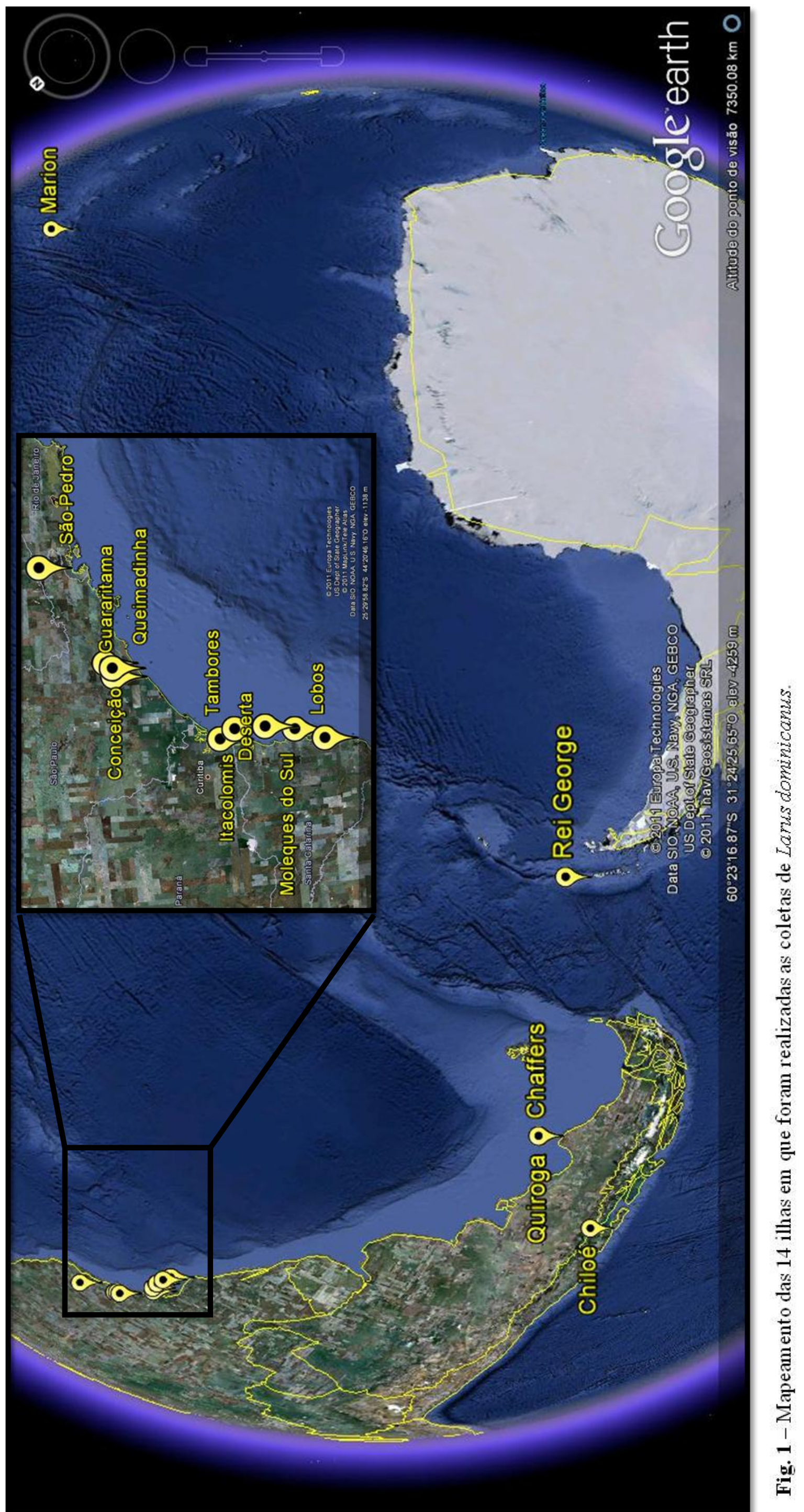


Extração do DNA e amplificação dos microssatélites

O DNA foi extraído do tecido sanguíneo com a utilização da técnica convencional de digestão com proteinase $\mathrm{K}$ e posterior purificação com fenol/clorofórmio ou acetato de amônio (Sambrook et al. 2001). O produto foi verificado em gel de agarose $1 \%$ e diluído para estoque a $25 \mathrm{ng} / \mu \mathrm{L}$.

Para amplificação, foram utilizados oito primers de microssatélites, marcados com as fluorescências HEX, TET e FAM. Os primers utilizados foram HG16, HG18, HG25 (Crochet et al., 2003), RBG13, RBG20, RBG27, RBG28 (Given et al., 2002) e K32 (Tirard et al., 2002). As reações em cadeia de polimerases (PCRs) foram feitas para um volume final de $10 \mu \mathrm{L}$, contendo tampão $1 \mathrm{X}, 2 \mathrm{mM}$ de dNTPs, $2,5 \mu \mathrm{M}$ de $\mathrm{MgCl}_{2}, 0,5 \mathrm{u}$ de Taq polymerase Platinum, 25ng de DNA e uma quantidade de primer variável para cada marcador (Tabela II). As reações foram realizadas em termocicladores, mantendo $95^{\circ} \mathrm{C}$ por 5 minutos, 35 ciclos de $95^{\circ} \mathrm{C}$ a 30 segundos, temperatura de anelamento por 30 segundos (Tabela II), $72^{\circ} \mathrm{C}$ por 1 minuto e uma extensão final de $10 \mathrm{~min}$ a $72^{\circ} \mathrm{C}$.

Tabela II - Temperaturas de anelamento e concentrações dos primers de microssatélites utilizados para genotipagem dos indivíduos de Larus dominicanus.

\begin{tabular}{c|c|c}
\hline Primer & T anelamento $\left({ }^{\circ} \mathbf{C}\right)$ & Concentração (pmol) \\
\hline HG16 & 57,5 & 2 \\
\hline HG18 & 65,7 & 2 \\
\hline HG25 & 60,9 & 2 \\
\hline RBG13 & 56,0 & 2 \\
\hline RBG20 & 47,5 & 1 \\
\hline RBG27 & 58,0 & 2 \\
\hline RBG28 & 58,0 & 2 \\
\hline K32 & 57,7 & 4 \\
\hline
\end{tabular}


$\mathrm{O}$ produto da PCR foi verificado em gel de agarose $2 \%$ e aqueles amplificados em boa qualidade foram diluídos 1:15, para os primers marcados com TET e FAM, ou 1:5, para os primers marcados com $\mathrm{HEX} ; 0,5 \mu \mathrm{L}$ do produto diluído foi misturado a $9 \mu \mathrm{L}$ de formamida e $0,5 \mu \mathrm{L}$ de ROX para ser genotipado no seqüenciador automático PE Applied Biosystems ABI-310. Os resultados foram analisados no programa Gene Scan para determinação dos tamanhos dos alelos. A Tabela III mostra o número de amostras genotipadas para cada loci em cada uma das colônias e a porcentagem de amostras que não puderam ser genotipadas (do inglês, missing data).

Tabela III - Número de amostras genotipadas por loci em cada uma das supostas colônias e quantidade de amostras não genotipadas (missing data)

\begin{tabular}{|l|r|r|r|r|r|r|r|r|}
\hline & RBG28 & K32 & RBG13 & RBG27 & RBG20 & HG16 & HG18 & HG25 \\
\hline São Pedro & 12 & 12 & 11 & 12 & 11 & 11 & 11 & 10 \\
\hline Queimadinha & 9 & 9 & 9 & 9 & 9 & 9 & 9 & 9 \\
\hline Guararitama & 84 & 85 & 81 & 83 & 84 & 78 & 82 & 80 \\
\hline Conceição & 6 & 6 & 6 & 6 & 6 & 6 & 6 & 6 \\
\hline Moleques do Sul & 34 & 34 & 34 & 33 & 34 & 32 & 33 & 32 \\
\hline Deserta & 14 & 14 & 12 & 14 & 14 & 13 & 13 & 14 \\
\hline Itacolomis & 5 & 5 & 5 & 5 & 5 & 3 & 4 & 5 \\
\hline Tambores & 10 & 10 & 9 & 10 & 10 & 10 & 9 & 9 \\
\hline Lobos & 14 & 14 & 14 & 14 & 14 & 12 & 13 & 14 \\
\hline Chiloé & 6 & 7 & 6 & 5 & 6 & 4 & 6 & 7 \\
\hline Quiroga & 19 & $\mathbf{2 0}$ & $\mathbf{2 0}$ & 19 & $\mathbf{2 0}$ & 9 & 17 & 18 \\
\hline Chaffers & 20 & 16 & $\mathbf{2 0}$ & $\mathbf{2 0}$ & $\mathbf{2 1}$ & 11 & 19 & 18 \\
\hline Marion & 5 & 5 & 6 & 5 & 5 & 5 & 5 & 6 \\
\hline Rei George & 16 & 16 & 15 & 16 & 16 & 14 & 15 & 15 \\
\hline TOTAL & $\mathbf{2 5 4}$ & $\mathbf{2 5 3}$ & $\mathbf{2 4 8}$ & $\mathbf{2 5 1}$ & $\mathbf{2 5 5}$ & $\mathbf{2 1 7}$ & $\mathbf{2 4 2}$ & $\mathbf{2 4 3}$ \\
\hline Missing data & $\mathbf{1 , 9 \%}$ & $\mathbf{2 , 3 \%}$ & $\mathbf{4 , 2 \%}$ & $\mathbf{3 , 1 \%}$ & $\mathbf{1 , 5 \%}$ & $\mathbf{1 6 , 2 \%}$ & $\mathbf{6 , 6 \%}$ & $\mathbf{6 , 2 \%}$ \\
\hline
\end{tabular}

\section{Análise dos dados}

O programa MicroChecker foi utilizado para testar erros de genotipagem ou a presença de alelos nulos, o teste foi realizado para cada uma das colônias. 
Foi realizado o teste para desvios no equilíbrio de Hardy-Weimberg e equilíbrio de ligação dentro de cada colônia e para cada um dos loci, assim como para todas as colônias e todos os loci juntos. Inicialmente, as amostras de mesma localidade e anos de coleta diferentes foram analisadas em conjunto, passando a serem consideradas separadamente em caso de desvio significativo do equilíbrio de Hardy-Weimberg. Neste último caso, foi calculado o $\mathrm{F}_{\mathrm{st}}$ entre os grupos de amostras de anos diferentes para verificar uma possível diferenciação entre os anos. Na ilha de Algaborro, no Chile, foram coletadas apenas três amostras, um número pequeno para estudos de genética de populações, assim, optou-se por excluir esta ilha das análises, mantendo-se apenas as amostras da ilha de Chiloé.

A caracterização da variabilidade genética de cada grupo foi analisada através dos cálculos das frequiências alélicas dentro de cada colônia (com a construção de gráficos de bolhas), da riqueza alélica, da riqueza de alelos privados e das taxas de heterozigose observadas. Para cálculo das frequiências alélicas e das taxas de heterozigose, foi utilizado o programa GENALEX (Peakall \& Smouse, 2005). Para o cálculo das riquezas alélicas e de alelos privados, foi utilizado o programa $H P-R A R E$ (Kalinowski, 2004), que oferece a possibilidade de normalizar a estimativa em função do tamanho amostral, uma vez que populações com maior número de amostras tendem a apresentar maior número absoluto de alelos e maior número de alelos privados. A normalização reduz o viés das análises em populações que diferem com grande intensidade no número de indivíduos coletados. As amostras foram normalizadas em função do menor número de indivíduos genotipados para um dado locus em uma dada colônia, que corresponde a três. O teste t de Student, um teste paramétrico, foi usado para verificar se a diferença entre as taxas de heterozigose, as riquezas alélicas e as 
riquezas de alelos privados apresentavam diferenças significativas entre os pares de colônias.

A distribuição da variação genética entre as colônias foi analisada a partir da análise de variância molecular (Analysis of Molecular Variance - AMOVA), com o auxílio do programa ARLEQUIM v. 3.0 (Excoffier et al., 2005). A análise foi realizada com as colônias sem nenhum agrupamento e, posteriormente, agrupadas de acordo com os países ou região de origem.

A diferenciação genética entre as colônias foi estimada através do cálculo do $\mathrm{F}_{\mathrm{st}}$. O cálculo foi realizado para as colônias par a par, utilizando o programa GENALEX, que faz uso do método de AMOVA. Este método cria matrizes de comparações entre os dados, extraindo um maior número de informações do que é extraído apenas com o cálculo simples das distâncias (Excoffier et al., 1992). O F $\mathrm{st}_{\mathrm{st}}$ foi desenvolvido para medir a proporção da taxa de heterozigose em função da estruturação populacional, utilizando dados de sequências de DNA. Índices análogos ao $\mathrm{F}_{\mathrm{st}}$ foram desenvolvidos ao longo do tempo para serem aplicados a outros tipos de dados moleculares, entre eles o $\mathrm{R}_{\text {st }}($ Pearse \& Crandall, 2004). Este índice considera o modelo mutacional passo a passo (Stepwise Mutation Model, SMM), sendo aparentemente mais apropriado para o uso em dados de microssatélites, no entanto, é sensível à alta variância na amostra. A variância aumenta com o baixo número de indivíduos amostrados ou com o baixo número de loci analisados. Nestes casos, o $\mathrm{F}_{\text {st }}$ pode apresentar uma estimativa mais acurada (Raymond \& Rousset, 1995). Uma vez que apenas oito loci estão envolvidos neste trabalho e que o número de indivíduos amostrados é baixo em algumas colônias (menor que dez indivíduos), optou-se por estimar o valor de $\mathrm{F}_{\text {st }}$ e não de $\mathrm{R}_{\mathrm{st}}$ para o estudo de diferenciação populacional. 
A fim de verificar a ocorrência de diferença sexual na dispersão, o sexo de alguns indivíduos foi identificado pelo método de sexagem molecular (Griffiths, 1998) e posteriormente foram calculados os valores de $F_{\text {st }}$ separadamente para fêmeas e machos. No total, foi identicado o sexo de 20 indivíduos de Moleques do Sul e 25 de Guararitama.

Uma eventual correlação entre os índices de diferenciação genética e as distâncias geográficas entre todos os pares de ilhas foi testada utilizando-se o teste de Mantel, que foi realizado com o auxílio do programa Mantel Nonparametric Test Calculator v.2.0 (Liedloff, 1999), com 10.000 randomizações. As distâncias entre as ilhas foram calculadas a partir das coordenadas geográficas, com o auxílio do programa SULCON, considerando uma linha reta. A única exceção foi o cálculo das distâncias entre Brasil e Chile e Argentina e Chile. Uma vez que as aves não atravessam grandes distâncias de terra, devido à necessidade de forrageamento ao longo da migração, a distância entre estas ilhas foi calculada considerando-se pontos ao longo da costa que se estendem da colônia chilena até as colônias brasileiras e argentinas; os pontos considerados foram Isla Magdalena e Ushuaia.

Em conjunto com os índices de diferenciação genética, foram utilizados métodos de classificação de clusters de indivíduos para inferir a estrutura populacional de $L$. dominicanus, com o auxílio dos programas STRUCTURE (Pritchard et al., 2000) e BAPS (Corander et al., 2008). As análises realizadas no STRUCTURE tiveram burning e tamanho de cadeia de $10.000,100.000$ e 10.000.000. Foi considerado o modelo de ancestralidade em que o indivíduo pode ser resultante do cruzamento entre indivíduos de duas populações diferentes e as freqüências alélicas foram consideradas independentes entre as populações, evitando subestimativas do valor de $\mathrm{k}$. $\mathrm{O}$ valor de $\mathrm{k}$ foi estimado através do método de Evanno et al. (2005). Além do valor de maior 
verossimilhança para $\mathrm{k}$, outros valores foram testados, buscando verificar a existência de alguma estrutura populacional. No programa $B A P S$, as análises foram realizadas em dois níveis: clusters de indivíduos e clusters de populações. Para ambos, as análises foram realizadas testando valores de k entre 2 e 14 e cinco corridas foram realizadas para cada valor de k, buscando verificar a convergência entre elas. No nível de clusters de populações, primeiramente foram rodadas as análises em que não é considerada a múltipla ancestralidade de um indivíduo, os dados gerados foram usados para rodar novas análises, nas quais um indivíduo pode ser atribuído proporcionalmente a populações diferentes, de acordo com a sua descendência.

Uma vez caracterizadas as populações, as diferenciações entre elas e a provável estrutura populacional, foram, então, calculadas as taxas de migração. Estas taxas foram estimadas no tempo recente, que identifica migrantes de até duas gerações anteriores, com o uso do programa Bayesass+ (Wilson \& Rannala, 2003). A estratégia adotada foi comparar as taxas de fluxo gênico recente com a estrutura populacional genética observada, considerando ainda que, em populações não equilibradas, a estrutura populacional não reflete o fluxo gênico, uma vez que a ausência de estrutura pode ser o resultado de diferenciação recente.

A ocorrência de eventuais gargalos populacionais foi testada com o auxílio do programa BOTTLENECK (Piry et al., 2007), utilizando-se o modelo mutacional TPM. Este modelo assume dois parâmetros mutacionais: a variância no tamanho da repetição envolvida na mutação $\left(\right.$ sigma $\left.{ }_{\mathrm{m}}\right)$ e a porcentagem de mutações que não ocorrem por adição ou deleção de uma única unidade repetitiva (p_g). Os valores destes parâmetros variam em função das características dos microssatélites. Quando os valores são superestimados, pode ocorrer a detecção de gargalo sem que ele de fato tenha ocorrido. Por outro lado, a subestimação destes parâmetros pode levar à não detecção de um 
gargalo que de fato ocorreu (Williamson-Natesan, 2005). Em função disso, múltiplas análises com combinações destes parâmetros foram realizadas, a fim de excluir erros de detecção do gargalo. Foram utilizados valores de 1, 2, 4, 8 e 16 para sigma ; e valores de $2 \%, 4 \%, 6 \%, 12 \%, 20 \%$ e 30\% para p_g. Estas combinações totalizaram 30 análises

para cada colônia amostrada. O teste utilizado foi o Wilcoxon teste, que é mais poderoso e robusto para baixos tamanhos amostrais (Luikart \& Cornuet, 1999). Os valores das probabilidades de que o excesso de taxas de heterozigose tenha ocorrido ao acaso foram plotados em gráficos tridimensionais com os eixos: sigma $\mathrm{m}_{\mathrm{m}} \mathrm{p} \_\mathrm{g}$ x $\mathrm{P}$ (excesso de taxa de heterozigose). Os valores de $\mathrm{P}$ abaixo de 0,05 indicam que o excesso de heterozigose não ocorreu ao acaso, apontando uma possível ocorrência de gargalo populacional recente. Em caso de identificação de alelos nulos em alguma das colônias, o locus foi excluído da análise para aquela colônial.

\section{RESULTADOS}

Testes de desvios

As análises realizadas pelo Microchecker apontaram evidências para alelos nulos no locus HG18, na Ilha de Rei George (Península Antártica). Todas as demais localidades não apresentaram evidências para a presença de alelos nulos, erros de genotipagem ou alelos que não amplificam estocasticamente em heterozigotos. De acordo com Dakin \& Avise (2004), é possível que os alelos nulos tenham um menor impacto sobre análises de estrutura populacional do que se observa em análises de parentesco. $\mathrm{O}$ cálculo dos índices de $\mathrm{F}_{\mathrm{st}}$ entre os pares de populações, as análises de Bayesiana para agrupamento populacional no BAPS e os testes de gargalos foram realizados com e sem a exclusão do locus HG18. Não foi observada divergência entre 
os resultados, assim, optou-se por utilizar os resultados de todas as análises sem a exclusão deste marcador.

Nenhuma das colônias apresentou desvio para o equilíbrio de ligação. Já para o equilíbrio de Hardy-Weimberg, as colônias de Guararitama e de Rei George apresentaram desvios significativos. O desvio nas amostras da ilha de Rei George foi significativo apenas no locus $\mathrm{HG} 18$, portanto, deve ser decorrente da presença de alelos nulos, conforme apontado anteriormente pelas análises do Microchecker. Em Guararitama, os loci RBG13, HG16 e HG18 apresentaram desvios. Para essa localidade há amostras de anos diferentes, que inicialmente foram analisadas em conjunto. A fim verificar se o desvio decorria de um ou mais anos de coleta, o teste foi realizado para cada ano separadamente. As amostras coletadas em 2004 apresentaram desvio significativo e foram retiradas das análises. O novo teste revelou um desvio significativo persistente para o conjunto de amostras dos anos de 2001, 2003 e 2005. Buscando verificar se uma diferenciação genética entre os anos de coleta estaria provocando o desvio de Hardy-Weimberg, foram estimados os valores de $\mathrm{F}_{\text {st }}$ para os pares de grupos. Conforme a Tabela IV, nenhuma diferenciação genética entre os anos foi observada. A fim de eliminar o problema do desvio, optou-se, então, por manter nas análises apenas um ano de coleta de Guararitama. Foi escolhido o ano de 2001, que não apresentou desvio para o equilíbrio de Hardy-Weimberg e no qual um maior número de amostras foram genotipadas. 
Tabela IV - $F_{\text {st }}$ entre os grupos de amostras dos quatro anos de coleta da ilha de Guararitama. Abaixo da diagonal estão os valores de $F_{\text {st }}$ e acima as probabilidades correspondentes.

\begin{tabular}{|l|c|c|c|c|}
\hline & GUA2001 & GUA2003 & GUA2004 & GUA2005 \\
\hline GUA2001 & 0,000 & 0,425 & 0,403 & 0,076 \\
\hline GUA2003 & 0,000 & 0,000 & 0,113 & 0,079 \\
\hline GUA2004 & 0,000 & 0,013 & 0,000 & 0,289 \\
\hline GUA2005 & 0,018 & 0,018 & 0,005 & 0,000 \\
\hline
\end{tabular}

As amostras de Moleques do Sul, também coletadas em diferentes anos, ao contrário de Guararitama, não apresentaram desvio para o equilíbrio de HardyWeimberg quando analisadas em conjunto, por isso, foram mantidas dentro em um único grupo.

\section{Caratcterização genética}

Foram encontrados no mínimo dois e no máximo seis alelos em cada locus. As frequiências de cada alelo estão expressas na Tabela $\mathrm{V}$ e podem ser visualizadas nos gráficos da Fig. 2 (a-h). Os gráficos mostram que, de uma maneira geral, as colônias apresentam distribuições de freqüências semelhantes, os alelos de maior freqüência são os mesmos na maioria das colônias. As localidades que apresentam maiores diferenças nas distribuições das freqüências alélicas são as das ilhas Marion (frequiências iguais entre os alelos 160 e 166 no RBG28 e fixação para o alelo 180 do HG16) e Rei George (Maior freqüência do alelo 172 no RBG28, RBG13 com maior freqüência do alelo 219). 
Tabela V - Frequências alélicas em cada população de Larus dominicanus.

\begin{tabular}{|c|c|c|c|c|c|c|c|c|c|c|c|c|c|c|c|}
\hline Locus & Alelo & SP & QUE & GUA & CONC & MOL & DES & ITA & TAM & LOB & CHI & QUI & CHA & MAR & RG \\
\hline \multirow[t]{3}{*}{ RBG28 } & 160 & 0,000 & 0,000 & 0,000 & 0,000 & 0,029 & 0,036 & 0,000 & 0,000 & 0,000 & 0,083 & 0,105 & 0,050 & 0,400 & 0,125 \\
\hline & 166 & 0,917 & 0,889 & 0,875 & 1,000 & 0,941 & 0,964 & 1,000 & 0,900 & 0,964 & 0,583 & 0,553 & 0,600 & 0,400 & 0,125 \\
\hline & 172 & 0,083 & 0,111 & 0,125 & 0,000 & 0,029 & 0,000 & 0,000 & 0,100 & 0,036 & 0,333 & 0,342 & 0,350 & 0,200 & 0,750 \\
\hline \multirow[t]{3}{*}{ K32 } & 123 & 0,250 & 0,389 & 0,340 & 0,667 & 0,441 & 0,321 & 0,500 & 0,350 & 0,321 & 0,071 & 0,350 & 0,469 & 0,700 & 0,500 \\
\hline & 127 & 0,000 & 0,000 & 0,060 & 0,083 & 0,029 & 0,036 & 0,000 & 0,000 & 0,000 & 0,000 & 0,000 & 0,000 & 0,000 & 0,000 \\
\hline & 133 & 0,750 & 0,611 & 0,600 & 0,250 & 0,529 & 0,643 & 0,500 & 0,650 & 0,679 & 0,929 & 0,650 & 0,531 & 0,300 & 0,500 \\
\hline \multirow[t]{6}{*}{ RBG13 } & 209 & 0,000 & 0,167 & 0,043 & 0,000 & 0,132 & 0,208 & 0,100 & 0,111 & 0,143 & 0,000 & 0,000 & 0,000 & 0,000 & 0,000 \\
\hline & 213 & 0,000 & 0,000 & 0,000 & 0,000 & 0,000 & 0,000 & 0,000 & 0,000 & 0,000 & 0,000 & 0,025 & 0,050 & 0,000 & 0,000 \\
\hline & 215 & 0,409 & 0,500 & 0,500 & 0,333 & 0,206 & 0,292 & 0,200 & 0,333 & 0,286 & 0,417 & 0,575 & 0,525 & 0,500 & 0,067 \\
\hline & 219 & 0,273 & 0,222 & 0,152 & 0,250 & 0,132 & 0,125 & 0,300 & 0,222 & 0,179 & 0,083 & 0,175 & 0,150 & 0,167 & 0,933 \\
\hline & 221 & 0,227 & 0,111 & 0,304 & 0,417 & 0,500 & 0,375 & 0,300 & 0,278 & 0,393 & 0,500 & 0,225 & 0,275 & 0,333 & 0,000 \\
\hline & 225 & 0,091 & 0,000 & 0,000 & 0,000 & 0,029 & 0,000 & 0,100 & 0,056 & 0,000 & 0,000 & 0,000 & 0,000 & 0,000 & 0,000 \\
\hline \multirow[t]{4}{*}{ RBG27 } & 190 & 0,292 & 0,222 & 0,130 & 0,417 & 0,167 & 0,179 & 0,000 & 0,150 & 0,071 & 0,000 & 0,368 & 0,250 & 0,000 & 0,406 \\
\hline & 192 & 0,625 & 0,556 & 0,630 & 0,500 & 0,727 & 0,679 & 0,900 & 0,750 & 0,821 & 0,600 & 0,421 & 0,375 & 0,700 & 0,313 \\
\hline & 194 & 0,000 & 0,000 & 0,000 & 0,000 & 0,000 & 0,036 & 0,000 & 0,000 & 0,000 & 0,200 & 0,026 & 0,075 & 0,200 & 0,000 \\
\hline & 196 & 0,083 & 0,222 & 0,239 & 0,083 & 0,106 & 0,107 & 0,100 & 0,100 & 0,107 & 0,200 & 0,184 & 0,300 & 0,100 & 0,281 \\
\hline \multirow[t]{2}{*}{ RBG20 } & 176 & 0,727 & 1,000 & 0,800 & 0,917 & 0,985 & 0,857 & 0,800 & 0,800 & 0,929 & 1,000 & 0,875 & 0,881 & 1,000 & 0,563 \\
\hline & 178 & 0,273 & 0,000 & 0,200 & 0,083 & 0,015 & 0,143 & 0,200 & 0,200 & 0,071 & 0,000 & 0,125 & 0,119 & 0,000 & 0,438 \\
\hline \multirow[t]{3}{*}{ HG16 } & 172 & 0,409 & 0,444 & 0,455 & 0,417 & 0,531 & 0,423 & 0,500 & 0,500 & 0,500 & 0,250 & 0,444 & 0,636 & 0,000 & 0,250 \\
\hline & 178 & 0,136 & 0,000 & 0,045 & 0,083 & 0,000 & 0,000 & 0,000 & 0,050 & 0,167 & 0,375 & 0,000 & 0,136 & 0,000 & 0,250 \\
\hline & 180 & 0,455 & 0,556 & 0,500 & 0,500 & 0,469 & 0,577 & 0,500 & 0,450 & 0,333 & 0,375 & 0,556 & 0,227 & 1,000 & 0,500 \\
\hline \multirow[t]{6}{*}{ HG18 } & 116 & 0,364 & 0,500 & 0,458 & 0,417 & 0,636 & 0,538 & 0,625 & 0,333 & 0,538 & 0,583 & 0,353 & 0,316 & 0,800 & 0,600 \\
\hline & 118 & 0,318 & 0,111 & 0,104 & 0,083 & 0,197 & 0,077 & 0,375 & 0,222 & 0,077 & 0,333 & 0,353 & 0,368 & 0,000 & 0,000 \\
\hline & 120 & 0,000 & 0,222 & 0,125 & 0,083 & 0,106 & 0,346 & 0,000 & 0,167 & 0,346 & 0,083 & 0,176 & 0,132 & 0,200 & 0,333 \\
\hline & 122 & 0,182 & 0,167 & 0,188 & 0,167 & 0,000 & 0,038 & 0,000 & 0,278 & 0,038 & 0,000 & 0,029 & 0,026 & 0,000 & 0,067 \\
\hline & 126 & 0,136 & 0,000 & 0,125 & 0,250 & 0,061 & 0,000 & 0,000 & 0,000 & 0,000 & 0,000 & 0,029 & 0,079 & 0,000 & 0,000 \\
\hline & 128 & 0,000 & 0,000 & 0,000 & 0,000 & 0,000 & 0,000 & 0,000 & 0,000 & 0,000 & 0,000 & 0,059 & 0,079 & 0,000 & 0,000 \\
\hline \multirow[t]{5}{*}{ HG25 } & 110 & 0,000 & 0,000 & 0,000 & 0,000 & 0,000 & 0,000 & 0,000 & 0,000 & 0,000 & 0,000 & 0,000 & 0,000 & 0,167 & 0,000 \\
\hline & 116 & 0,550 & 0,556 & 0,543 & 0,750 & 0,484 & 0,393 & 0,500 & 0,111 & 0,429 & 0,571 & 0,500 & 0,639 & 0,833 & 0,733 \\
\hline & 118 & 0,450 & 0,444 & 0,457 & 0,250 & 0,516 & 0,607 & 0,500 & 0,889 & 0,571 & 0,357 & 0,472 & 0,333 & 0,000 & 0,267 \\
\hline & 120 & 0,000 & 0,000 & 0,000 & 0,000 & 0,000 & 0,000 & 0,000 & 0,000 & 0,000 & 0,000 & 0,028 & 0,000 & 0,000 & 0,000 \\
\hline & 124 & 0,000 & 0,000 & 0,000 & 0,000 & 0,000 & 0,000 & 0,000 & 0,000 & 0,000 & 0,071 & 0,000 & 0,028 & 0,000 & 0,000 \\
\hline
\end{tabular}




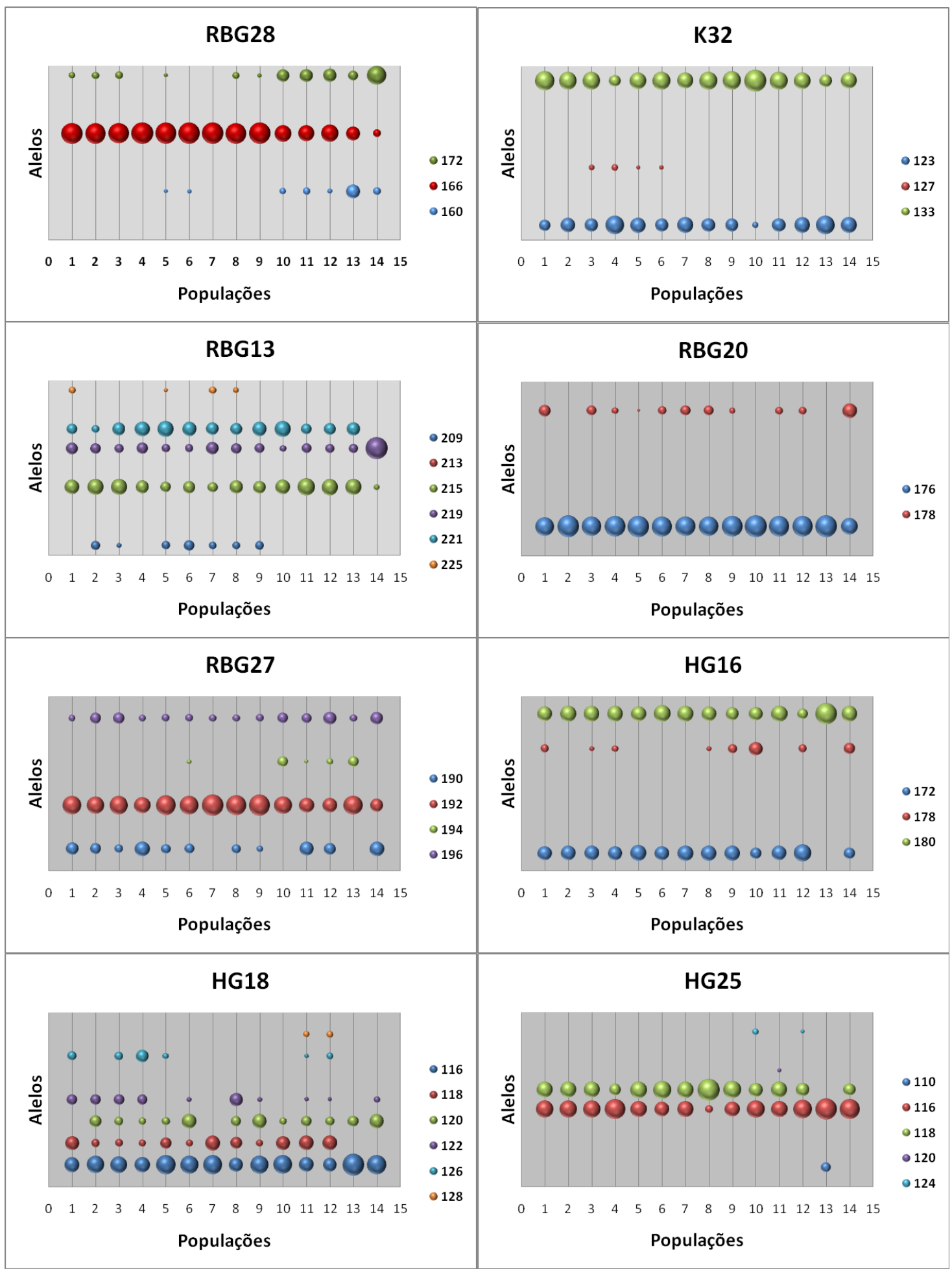

Fig. 2 - Distribuição das frequiências alélicas nas colônias. Cada gráfico representa um locus, no qual cada cor de esfera representa uma classe de alelos e o raio da esfera representa a freqüência alélica. As colônias estão numeradas de 1 a 14, sendo: 1- São Pedro, 2- Queimadinha, 3- Guararitama, 4- Laje da Conceição, 5- Moleques do Sul, 6- Deserta, 7- Itacolomis, 8- Tambores, 9- Lobos, 10- Chiloé, 11Quiroga, 12- Chaffers, 13- Marion, 14- Rei George. 
As taxas de heterozigose observadas estão expressas na Tabela VI. A maior média das taxas de heterozigose foi observada na colônia de Chaffers, seguida por Quiroga. A menor média foi observada na colônia de Marion. O teste $\mathrm{t}$ de Student mostrou que as diferenças entre as taxas de heterozigose de Chaffers e Marion e de Quiroga e Marion são significativas. Também apresentaram diferenças significativas as taxas de heterozigose de Guararitama e Lobos.

Tabela VI - Taxas de heterozigose observadas em cada uma das colônias por locus e a média entre os loci por colônia de Larus dominicanus.

\begin{tabular}{|l|r|r|r|r|r|r|r|r|r|}
\hline Pop & RBG28 & \multicolumn{1}{|c|}{ K32 } & RBG13 & RBG27 & RBG20 & HG16 & HG18 & HG25 & Média \\
\hline SP & 0,167 & 0,500 & 0,818 & 0,417 & 0,545 & 0,273 & 0,545 & 0,700 & 0,496 \\
\hline QUE & 0,222 & 0,333 & 0,778 & 0,556 & 0,000 & 0,667 & 0,667 & 0,667 & 0,486 \\
\hline GUA & 0,250 & 0,400 & 0,696 & 0,478 & 0,320 & 0,636 & 0,667 & 0,565 & 0,502 \\
\hline CONC & 0,000 & 0,500 & 0,500 & 0,833 & 0,167 & 0,500 & 0,667 & 0,500 & 0,458 \\
\hline MOL & 0,118 & 0,676 & 0,588 & 0,455 & 0,029 & 0,500 & 0,606 & 0,406 & 0,422 \\
\hline DES & 0,071 & 0,714 & 0,917 & 0,429 & 0,143 & 0,538 & 0,462 & 0,357 & 0,454 \\
\hline ITA & 0,000 & 0,600 & 0,600 & 0,200 & 0,400 & 0,333 & 0,750 & 0,600 & 0,435 \\
\hline TAM & 0,200 & 0,700 & 0,889 & 0,400 & 0,400 & 0,500 & 0,889 & 0,000 & 0,497 \\
\hline LOB & 0,071 & 0,357 & 0,786 & 0,214 & 0,143 & 0,500 & 0,538 & 0,571 & 0,398 \\
\hline CHI & 0,667 & 0,143 & 0,333 & 0,800 & 0,000 & 0,500 & 0,833 & 0,857 & 0,517 \\
\hline QUI & 0,684 & 0,500 & 0,600 & 0,684 & 0,250 & 0,667 & 0,882 & 0,500 & 0,596 \\
\hline CHA & 0,700 & 0,438 & 0,750 & 0,800 & 0,238 & 0,455 & 0,789 & 0,611 & 0,598 \\
\hline MAR & 0,400 & 0,600 & 0,333 & 0,600 & 0,000 & 0,000 & 0,400 & 0,000 & 0,292 \\
\hline RG & 0,500 & 0,625 & 0,133 & 0,688 & 0,500 & 0,571 & 0,133 & 0,400 & 0,444 \\
\hline
\end{tabular}

A riqueza alélica e a riqueza de alelos privados, corrigidas em função do número de indivíduos amostrados em cada colônia, estão expressas, respectivamente, nas Tabelas VII e VIII. Chaffers e Quiroga apresentaram as maiores médias de riquezas alélicas e Marion apresentou a menor média. Embora exista variação nos valores de riqueza alélica entre as localidades, esta variação é baixa, o teste t mostrou uma diferença significativa apenas entre as riquezas alélicas de São Pedro e Lobos, Queimadinha e Chaffers, Guararitama e Moleques do Sul, Chaffers e Moleques do Sul. 
Os valores de riqueza de alelos privados não apresentaram diferenças significativas entre as colônias. O maior valor foi apresentado pelas ilhas Marion.

Tabela VII - Riquezas alélicas corrigidas em função dos tamanhos amostrais de cada colônia.

\begin{tabular}{|l|r|r|r|r|r|r|r|r|r|}
\hline & RBG28 & \multicolumn{1}{|c|}{ K32 } & \multicolumn{1}{|c|}{ RBG13 } & RBG27 & RBG20 & HG16 & HG18 & \multicolumn{1}{c|}{ HG25 } & Média \\
\hline SP & 1,45 & 1,86 & 3,40 & 2,35 & 1,89 & 2,60 & 3,28 & 1,99 & 2,35 \\
\hline QUE & 1,57 & 1,97 & 3,13 & 2,68 & 1,00 & 1,99 & 3,13 & 1,99 & 2,18 \\
\hline GUA & 1,77 & 2,18 & 3,04 & 2,45 & 1,61 & 2,05 & 3,37 & 1,97 & 2,31 \\
\hline CONC & 1,00 & 2,41 & 2,87 & 2,49 & 1,50 & 2,49 & 3,67 & 1,91 & 2,29 \\
\hline MOL & 1,34 & 2,14 & 3,10 & 2,18 & 1,09 & 1,97 & 2,57 & 1,98 & 2,05 \\
\hline DES & 1,21 & 2,14 & 3,27 & 2,48 & 1,64 & 1,98 & 2,59 & 1,97 & 2,16 \\
\hline ITA & 1,00 & 2,00 & 4,00 & 1,60 & 1,87 & 2,00 & 2,00 & 2,00 & 2,06 \\
\hline TAM & 1,52 & 1,96 & 3,60 & 2,20 & 1,79 & 2,28 & 3,43 & 1,57 & 2,29 \\
\hline LOB & 1,21 & 1,93 & 3,24 & 1,92 & 1,39 & 2,65 & 2,59 & 1,98 & 2,11 \\
\hline CHI & 2,47 & 1,43 & 2,49 & 2,73 & 1,00 & 2,96 & 2,47 & 2,40 & 2,24 \\
\hline QUI & 2,44 & 1,94 & 2,67 & 2,82 & 1,58 & 1,99 & 3,29 & 2,14 & 2,36 \\
\hline CHA & 2,22 & 1,98 & 2,80 & 3,10 & 1,56 & 2,47 & 3,45 & 2,10 & 2,46 \\
\hline MAR & 2,86 & 1,97 & 2,74 & 2,47 & 1,00 & 1,00 & 1,87 & 1,77 & 1,96 \\
\hline RG & 2,17 & 1,98 & 1,37 & 2,78 & 1,98 & 2,70 & 2,30 & 1,87 & 2,14 \\
\hline
\end{tabular}

Tabela VIII - Riquezas de alelos privados corrigidas em função dos tamanhos amostrais de cada colônia.

\begin{tabular}{|l|r|r|r|r|r|r|r|r|r|}
\hline & RBG28 & K32 & RBG13 & RBG27 & RBG20 & \multicolumn{1}{l|}{ HG16 } & HG18 & \multicolumn{1}{l|}{ HG25 } & Média \\
\hline SP & 0,00 & 0,00 & 0,38 & 0,00 & 0,00 & 0,00 & 0,01 & 0,00 & 0,05 \\
\hline QUE & 0,00 & 0,00 & 0,00 & 0,00 & 0,00 & 0,00 & 0,00 & 0,00 & 0,00 \\
\hline GUA & 0,00 & 0,07 & 0,03 & 0,00 & 0,00 & 0,00 & 0,04 & 0,00 & 0,02 \\
\hline CONC & 0,00 & 0,25 & 0,00 & 0,00 & 0,00 & 0,00 & 0,04 & 0,00 & 0,04 \\
\hline MOL & 0,00 & 0,05 & 0,02 & 0,00 & 0,00 & 0,00 & 0,00 & 0,00 & 0,01 \\
\hline DES & 0,00 & 0,07 & 0,00 & 0,00 & 0,00 & 0,00 & 0,00 & 0,00 & 0,01 \\
\hline ITA & 0,00 & 0,00 & 0,17 & 0,00 & 0,00 & 0,00 & 0,00 & 0,00 & 0,02 \\
\hline TAM & 0,00 & 0,00 & 0,06 & 0,00 & 0,00 & 0,00 & 0,00 & 0,00 & 0,01 \\
\hline LOB & 0,00 & 0,00 & 0,00 & 0,00 & 0,00 & 0,00 & 0,00 & 0,00 & 0,00 \\
\hline CHI & 0,00 & 0,00 & 0,00 & 0,05 & 0,00 & 0,00 & 0,00 & 0,36 & 0,05 \\
\hline QUI & 0,00 & 0,00 & 0,10 & 0,00 & 0,00 & 0,00 & 0,18 & 0,17 & 0,06 \\
\hline CHA & 0,00 & 0,00 & 0,23 & 0,00 & 0,00 & 0,00 & 0,26 & 0,10 & 0,07 \\
\hline MAR & 0,04 & 0,00 & 0,00 & 0,05 & 0,00 & 0,00 & 0,00 & 0,77 & 0,11 \\
\hline RG & 0,00 & 0,00 & 0,00 & 0,00 & 0,00 & 0,00 & 0,00 & 0,00 & 0,00 \\
\hline
\end{tabular}




\section{Diferenciação genética}

A AMOVA mostrou que, quando nenhum grupo é considerado, 91,23\% da variação ocorrem dentro das populações e apenas $8,77 \%$ entre as populações, sendo ambos os valores significativos $(\mathrm{p}=0,0000)$. Ao se dividir as populações em cinco grupos (Brasil, Chile, Argentina, Antártica e Subantártica), 12,03\% (p=0,0000) da variação ocorre entre os grupos, $1,31 \%(\mathrm{p}=0,0101)$ entre as populações e $86,66 \%$ $(\mathrm{p}=0,0000)$ dentro das populações (Tabela IX), todos os valores são significativos.

Tabela IX - Resultados da análise de variância molecular (AMOVA) em microssatélites de Larus dominicanus, com populações não agrupadas e agrupadas por países ou região de origem.

\begin{tabular}{|l|c|c|c|c|}
\cline { 2 - 5 } \multicolumn{1}{c|}{} & $\begin{array}{c}\mathbf{N}^{\circ} \text { de } \\
\text { grupos }\end{array}$ & $\begin{array}{c}\text { Componentes de } \\
\text { Variância }\end{array}$ & \% Variação & P-valor \\
\hline \multirow{2}{*}{ Com agrupamento } & \multirow{2}{*}{5} & Entre grupos & 12,03 & 0,0000 \\
\cline { 3 - 5 } & & Entre populações & 1,31 & 0,0101 \\
\cline { 3 - 5 } & \multirow{2}{*}{ Sem agrupamento } & Dentro das populações & 86,66 & 0,0000 \\
\hline & \multirow{2}{*}{1} & Entre populações & 8,77 & 0,0000 \\
\cline { 3 - 5 } & & Dentro das populações & 91,23 & 0,0000 \\
\hline
\end{tabular}

Os valores de $\mathrm{F}_{\text {st }}$ calculados para os pares de localidades estão expressos na Tabela X, abaixo da diagonal. Acima da diagonal estão os valores das probabilidades correspondentes. Em negrito, os valores significativos $(\mathrm{p}<0,05)$, que indicam diferenciação genética entre o par de localidades. As colônias de Marion e de Rei George apresentaram diferenciação significativa com todas as demais. As colônias da costa argentina apenas não apresentaram diferenciação entre si e entre Quiroga e São Pedro e Quiroga e Queimadinha. A colônia chilena de Chiloé não apresentou 
diferenciação significativa apenas com São Pedro. Entre as colônias brasileiras, apenas alguns pares apresentaram diferenciação significativa.

Tabela $\mathbf{X}$ - Valores de $\mathrm{F}_{\mathrm{st}}$ calculados para as localidades par a par (abaixo da diagonal) e respectivas probabilidades associadas (acima da diagonal). Os valores significativos estão sombreados e em negrito.

\begin{tabular}{|c|c|c|c|c|c|c|c|c|c|c|c|c|c|c|}
\hline & SP & QUE & GUA & CONC & MOL & DES & ITA & TAM & LOB & CHI & QUI & CHA & MAR & RG \\
\hline SP & & 0,369 & 0,451 & 0,158 & 0,002 & 0,076 & 0,451 & 0,130 & 0,049 & 0,057 & 0,053 & 0,006 & 0,000 & $\mathbf{0 , 0 0 0}$ \\
\hline QUE & 0,007 & & 0,450 & 0,278 & 0,076 & 0,438 & 0,439 & 0,067 & 0,285 & 0,020 & 0,205 & 0,021 & 0,002 & 0,000 \\
\hline GUA & 0,000 & 0,000 & & 0,184 & 0,001 & 0,250 & 0,453 & $\mathbf{0 , 0 3 7}$ & 0,110 & 0,015 & 0,004 & 0,001 & 0,000 & 0,000 \\
\hline CONC & 0,048 & 0,028 & 0,034 & & 0,058 & 0,044 & 0,353 & 0,003 & 0,018 & 0,002 & 0,006 & 0,016 & 0,005 & $\mathbf{0 , 0 0 0}$ \\
\hline MOL & 0,094 & 0,048 & 0,058 & 0,072 & & 0,252 & 0,430 & 0,002 & 0,254 & 0,002 & 0,000 & 0,000 & 0,000 & 0,000 \\
\hline DES & 0,045 & 0,000 & 0,012 & 0,095 & 0,011 & & 0,441 & 0,251 & 0,445 & 0,005 & $\mathbf{0 , 0 0 0}$ & 0,000 & 0,000 & $\mathbf{0 , 0 0 0}$ \\
\hline ITA & 0,000 & 0,000 & 0,000 & 0,018 & 0,000 & 0,000 & & 0,412 & 0,450 & 0,050 & 0,016 & 0,005 & 0,000 & 0,000 \\
\hline TAM & 0,041 & 0,072 & 0,054 & & 0,107 & 0,018 & 0,007 & & & 0,000 & & & 0,000 & 0,000 \\
\hline LOB & 0,054 & 0,017 & 0,027 & 0,116 & 0,012 & 0,000 & 0,000 & 0,032 & & 0,024 & 0,000 & 0,000 & 0,000 & 0,000 \\
\hline CHI & 0,067 & 0,103 & 0,080 & 0,219 & 0,148 & 0,128 & 0,115 & 0,196 & 0,087 & & 0,018 & 0,007 & 0,002 & $\mathbf{0 , 0 0 0}$ \\
\hline QUI & 0,043 & 0,022 & 0,052 & 0,124 & 0,155 & 0,109 & 0,110 & 0,129 & 0,145 & $\mathbf{0 , 0 7 7}$ & & 0,210 & 0,000 & $\mathbf{0 , 0 0 0}$ \\
\hline CHA & $\mathbf{0 , 0 7 8}$ & 0,067 & $\mathbf{0 , 0 7 3}$ & $\mathbf{0 , 0 9 3}$ & 0,165 & 0,168 & 0,116 & $\mathbf{0 , 1 8 7}$ & $\mathbf{0 , 1 5 3}$ & $\mathbf{0 , 0 8 9}$ & 0,012 & & 0,000 & $\mathbf{0 , 0 0 0}$ \\
\hline MAR & $\mathbf{0 , 2 9 7}$ & 0,225 & 0,240 & $\mathbf{0 , 1 9 8}$ & $\mathbf{0 , 3 0 2}$ & 0,284 & $\mathbf{0 , 2 3 9}$ & 0,412 & 0,319 & 0,257 & $\mathbf{0 , 2 5 0}$ & $\mathbf{0 , 2 9 3}$ & & 0,000 \\
\hline RG & 0,332 & 0,345 & 0,351 & 0,350 & 0,450 & 0,402 & 0,369 & 0,423 & 0,410 & 0,360 & 0,293 & 0,306 & 0,353 & \\
\hline
\end{tabular}

Foi testada a correlação entre os valores de $\mathrm{F}_{\mathrm{st}}$ e as distâncias geográficas entre os pares de localidades. O teste de Mantel revelou uma correlação positiva entre as distâncias genéticas e geográficas, com um valor de r=0,673, indicando uma alta correlação, e g=2,934, com uma probabilidade de 0,011 , mostrando que a correlação é significativa. Apesar desta correlação, o gráfico da Figura 3 mostra que os pares de localidades com maiores valores de $\mathrm{F}_{\mathrm{st}}$ são entre as colônias da costa brasileira e a da Península Antártica, ainda que as maiores distâncias geográficas ocorram em relação à ilha Marion. 


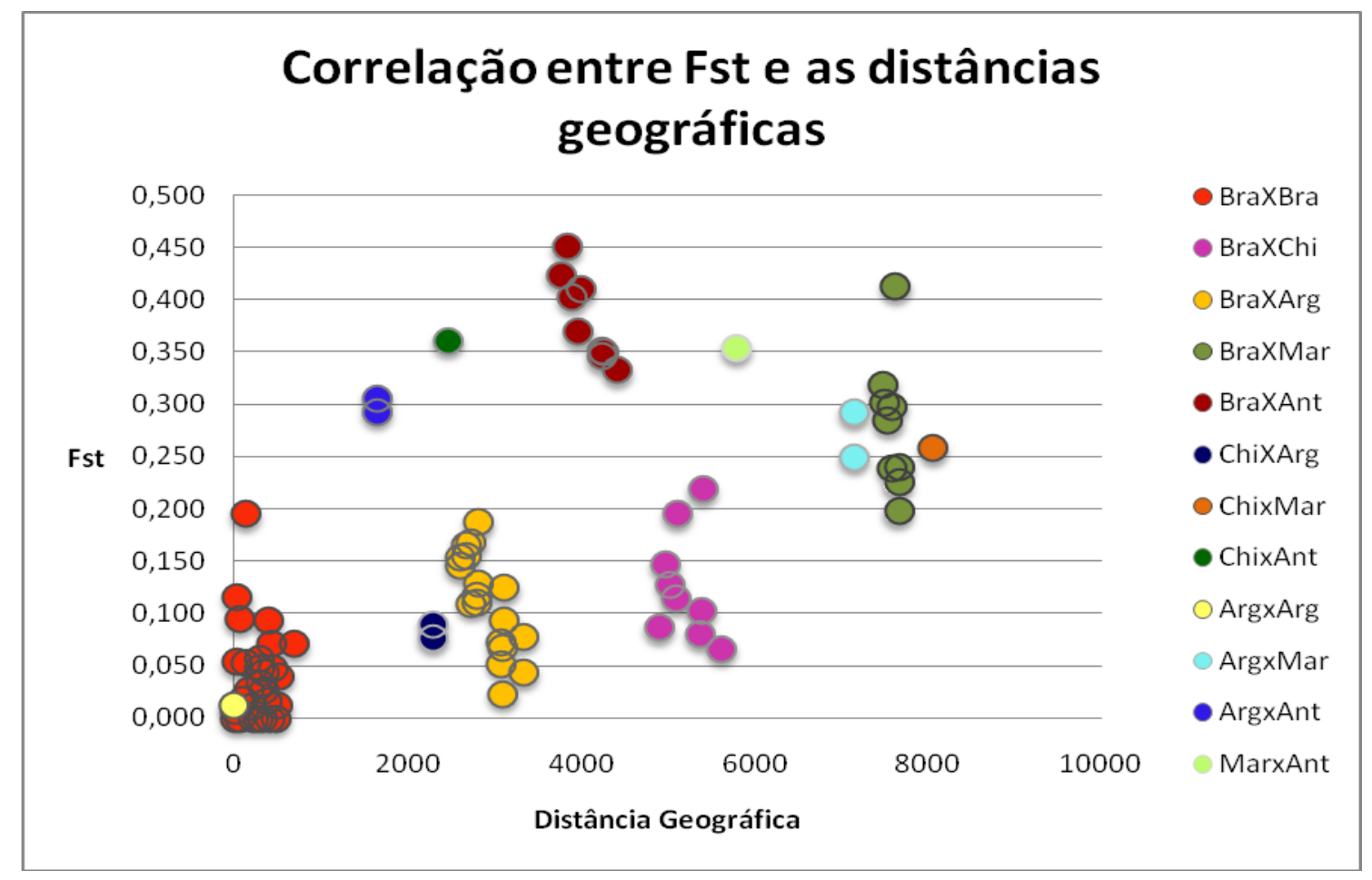

Fig. 3 - Correlação entre as distâncias geográficas e os valores de $\mathrm{F}_{\mathrm{st}}$ entre os pares de colônias. Cada cor representa uma combinação entre grupos de colônias de acordo com o país de origem.

Realizando-se o teste apenas para as colônias da costa brasileira, que apresentam pequenas distâncias entre si, observa-se que esta correlação é baixa e não significativa, com $r=0,2592, g=1,2882$ e $p=0,1179$ (Fig. 4). 


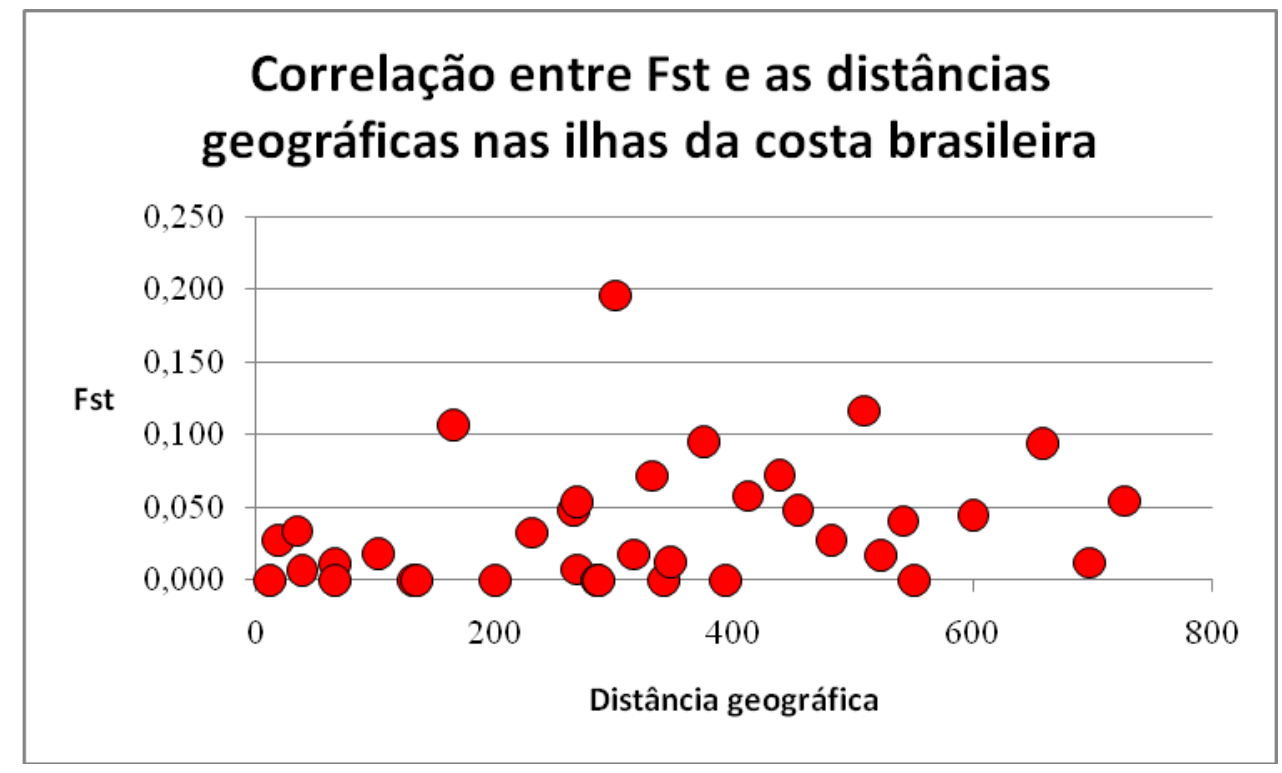

Fig. 4 - Correlação entre as distâncias geográficas e os valores de $F_{s t}$ entre os pares de colônias da costa brasileira.

Os valores de $\mathrm{F}_{\text {st }}$ calculados para os indivíduos para os quais o sexo foi identificado mostraram que as fêmeas apresentam o dobro de dispersão dos machos, já que os valores obtidos de $\mathrm{F}_{\text {st }}$ foram $\mathrm{F}_{\text {st } \mathrm{F}}=0,5$ e $\mathrm{F}_{\text {st } \mathrm{M}}=0,25$.

Por fim, para analisar a diferenciação genética e a estruturação populacional, foram realizados os agrupamentos em clusters. O resultado obtido através do programa STRUCTURE indicou que o número de populações com maior verossimilhança é k=2 (Fig. 5), mas nenhuma estrutura populacional foi identificada (Fig.6). Outros valores de k entre 2 e 14 foram testados e não revelaram estrutura populacional, independente dos tamanhos de burning ou de cadeia. 


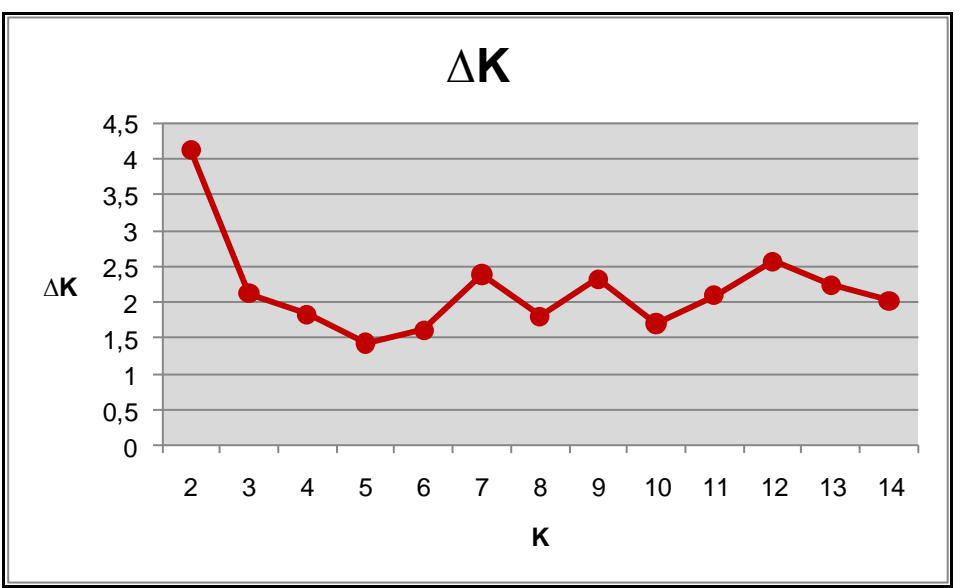

Fig. 5 - Valores de k calculados de acordo com o método de Evanno et al. (2005). O valor com maior verossimilhança, de acordo com este método é de $\mathrm{k}=2$.

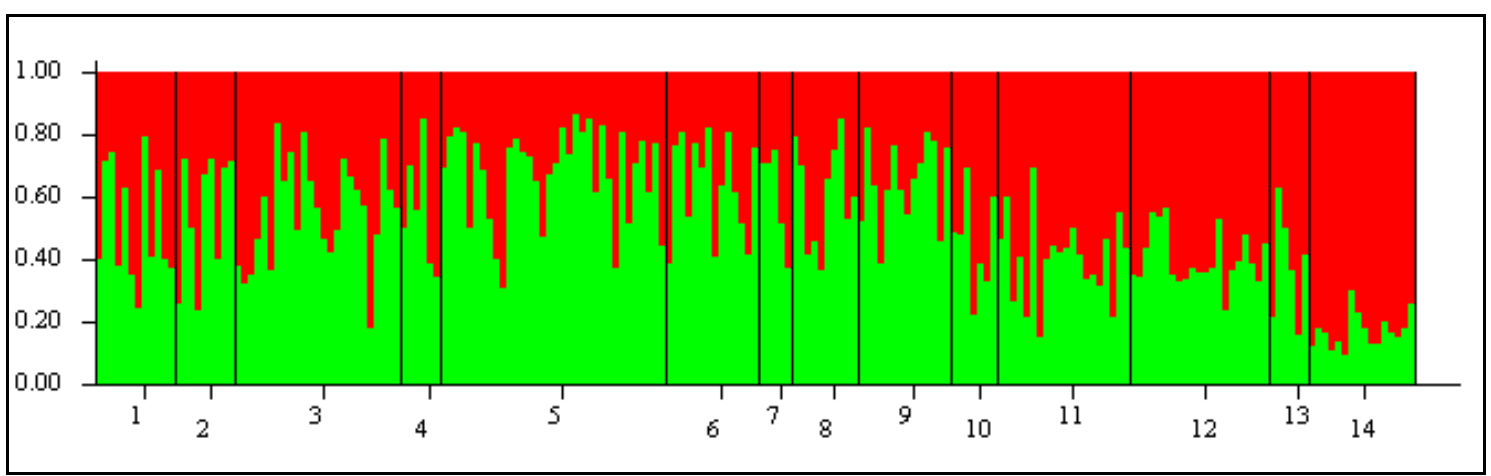

Fig. 6 - A figura mostra o resultado do agrupamento em clusters de indivíduos pelo programa STRUCTURE. Cada barra corresponde a um indivíduo, os grupos de indivíduos amostrados em uma mesma localidade estão divididos por uma linha preta. Observa-se a ausência de estruturação populacional.

De acordo com o programa BAPS, o número de populações com maior verossimilhança foi $\mathrm{k}=12$, mas, assim como no programa STRUCTURE, nenhuma estruturação foi observada (Fig. 7). 


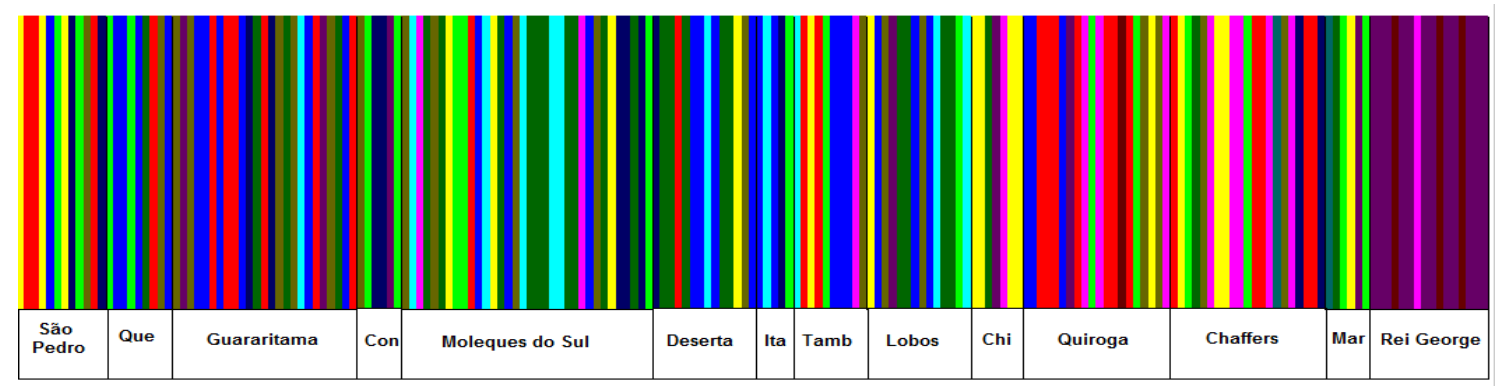

Fig. 7 - A figura mostra o resultado do agrupamento em clusters de indivíduos pelo programa BAPS. Cada barra corresponde a um indivíduo e os indivíduos estão agrupados de acordo com a localidade de origem. Nenhuma estruturação populacional foi observada.

O cluster de indivíduos não considera informações prévias sobre as populações de origem. Em função da baixa variabilidade alélica, do pequeno número de indivíduos amostrados em algumas das populações e do baixo número de loci em estudo, é possível que os dados não sejam suficientemente robustos para se obter uma resolução nas análises.

Assim, optou-se por outra abordagem oferecida pelo BAPS para formação de clusters que, para os dados em questão, pode apresentar melhores resultados: a formação de clusters de populações. Este método agrupa as localidades de origem da maneira mais provável, com base em análises de máxima verossimilhança e estatística Bayesiana. O cluster populacional revelou a existência de quatro grupos com homogenidade genética: as colônias brasileiras, as colônias das ilhas argentinas com a da ilha chilena, a colônia da ilha Marion e a colônia da Antártica (Fig. 8). 


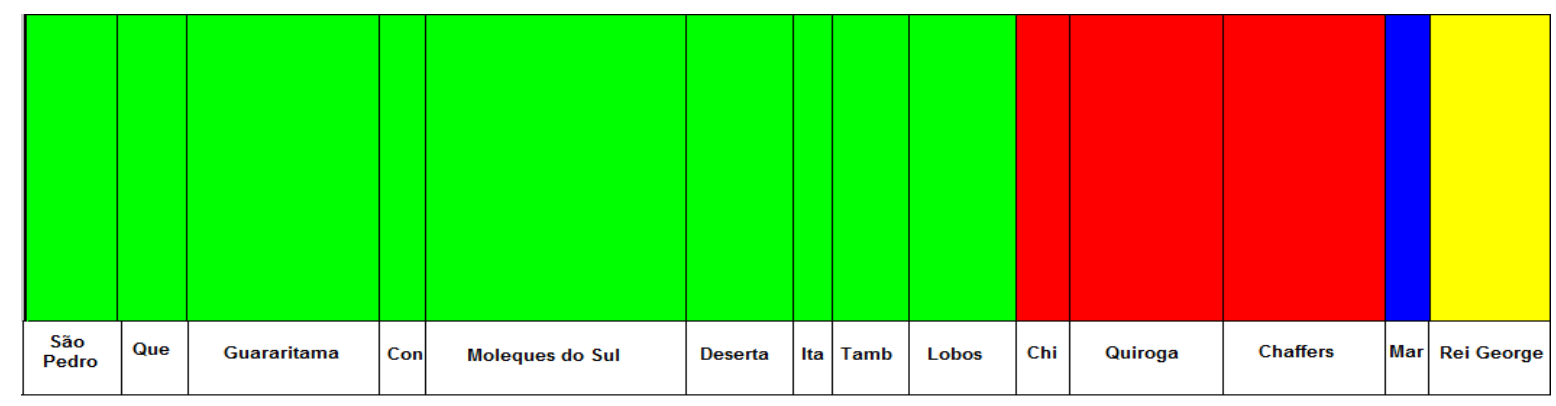

Fig. 8 - A figura mostra o resultado do cluster de grupos de indivíduos, com base nas populações de origem, fornecido pelo programa BAPS. Cada cor indica um grupo de genótipos associado a uma suposta população que engloba as subpopulações. A figura revela quatro supostas populações.

Com base nestes resultados, foi feita uma nova análise considerando que cada indivíduo pode ser um híbrido de indivíduos de mais de uma população. Esta análise revelou a presença de três indivíduos possivelmente migrantes ou descendentes de migrantes (Fig. 9). Em Guararitama há um indivíduo resultante do cruzamento entre um indivíduo das ilhas brasileiras e outro de Rei George. Em Moleques do Sul há um migrante das ilhas argentinas ou da ilha chilena. Em Quiroga há um indivíduo resultante do cruzamento entre um indivíduo de Rei George e outro mais provavelmente das ilhas argentinas ou da ilha chilena.

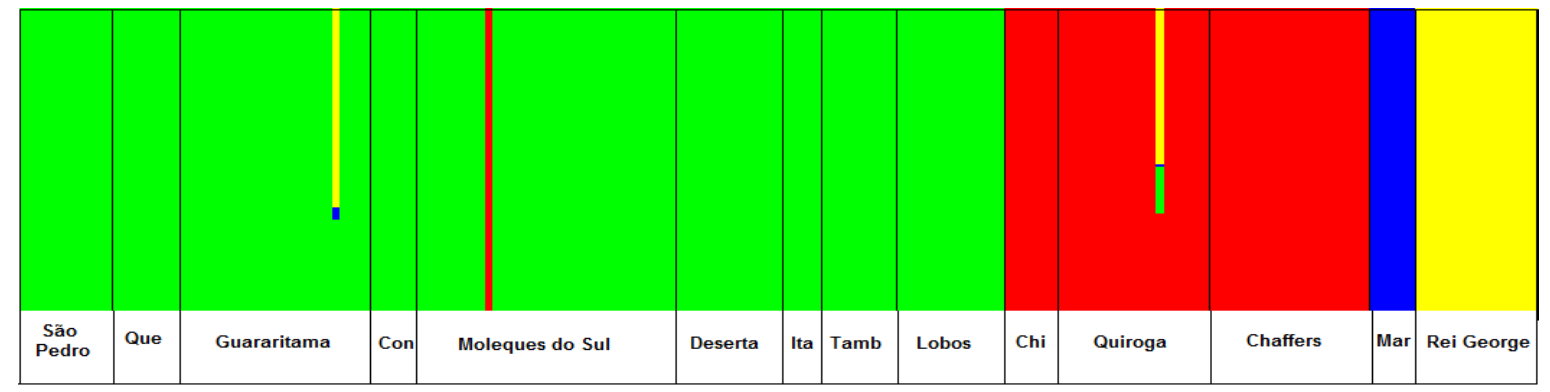

Fig. 9 - Na figura, observam-se possíveis migrantes ou descendentes de migrantes nas populações de Guararitama, Moleques do Sul e Quiroga. Resultado do cluster de populações, com presença de migrantes, fornecido pelo programa BAPS. 
Estimativas das taxas de migração

As taxas de migração recente, estimadas através do programa Bayesass + estão expressas na Tabela XI. Os valores da diagonal mostram as taxas de não-migrantes dentro de cada população. Estão em destaque os valores que apresentaram intervalos de confiança iguais ou superiores aos intervalos em casos de dados insuficientes para migrantes (Média =0,0417; CI=0 -0,1850) e não migrantes (Média=0,833; $\mathrm{CI}=0,675$ - 0,992). Observam-se baixas taxas de migração entre todos os grupos para os quais os dados não foram considerados insuficientes (intervalos de confiança mais estreitos que os de referência). A maior taxa de migração foi observada a partir do Brasil, em direção à Argentina, no entanto, com amplo intervalo de confiança. Observaram-se também altas taxas de migração a partir do Brasil e Argentina na direção do Chile, mas este último grupo apresenta uma amostragem muito baixa, que pode ter determinado a baixa consistência dos dados.

Tabela XI - Taxas de migração recentes, calculadas através do programa BAYESASS+. Em itálico e negrito, os valores para os quais provavelmente os dados foram insuficientes.

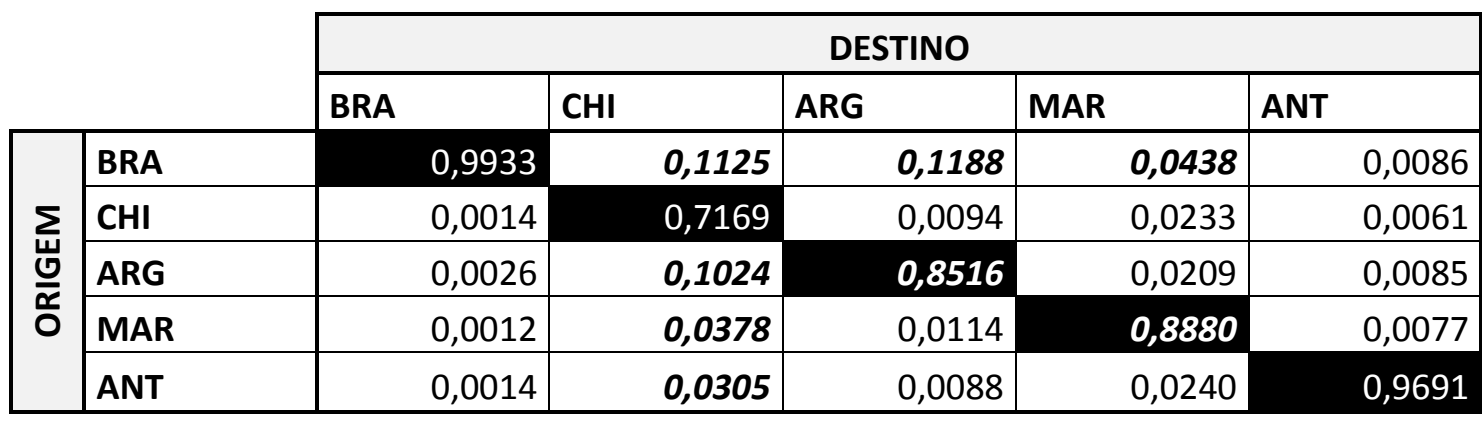




\section{Gargalo populacional}

Foram observados sinais de gargalo populacional em três colônias da costa brasileira (São Pedro, Queimadinha e Guararitama; Fig. 10), nas duas colônias da costa argentina e na colônia da Antártica (Fig. 11). À exceção de Quiroga, todas as colônias com sinal de gargalo apresentaram valores de $\mathrm{P}$ significativos para quaisquer combinações de sigma $a_{m}$ e p_g, indicando que o sinal de gargalo não foi um viés em função de estimativas errôneas destes parâmetros.

A colônia de Itacolomis apresentou gargalo significativo quando combinados valores baixos e intermediários de sigma $\mathrm{m}_{\mathrm{m}}$ com valores altos e intermediários de p_g. É possível que esta colônia também tenha sofrido gargalo, mas, como os resultados não foram uniformes e o tamanho amostral desta colônia é baixo $(\mathrm{N}=5)$, optou-se por não considerar o gargalo como significativo. 


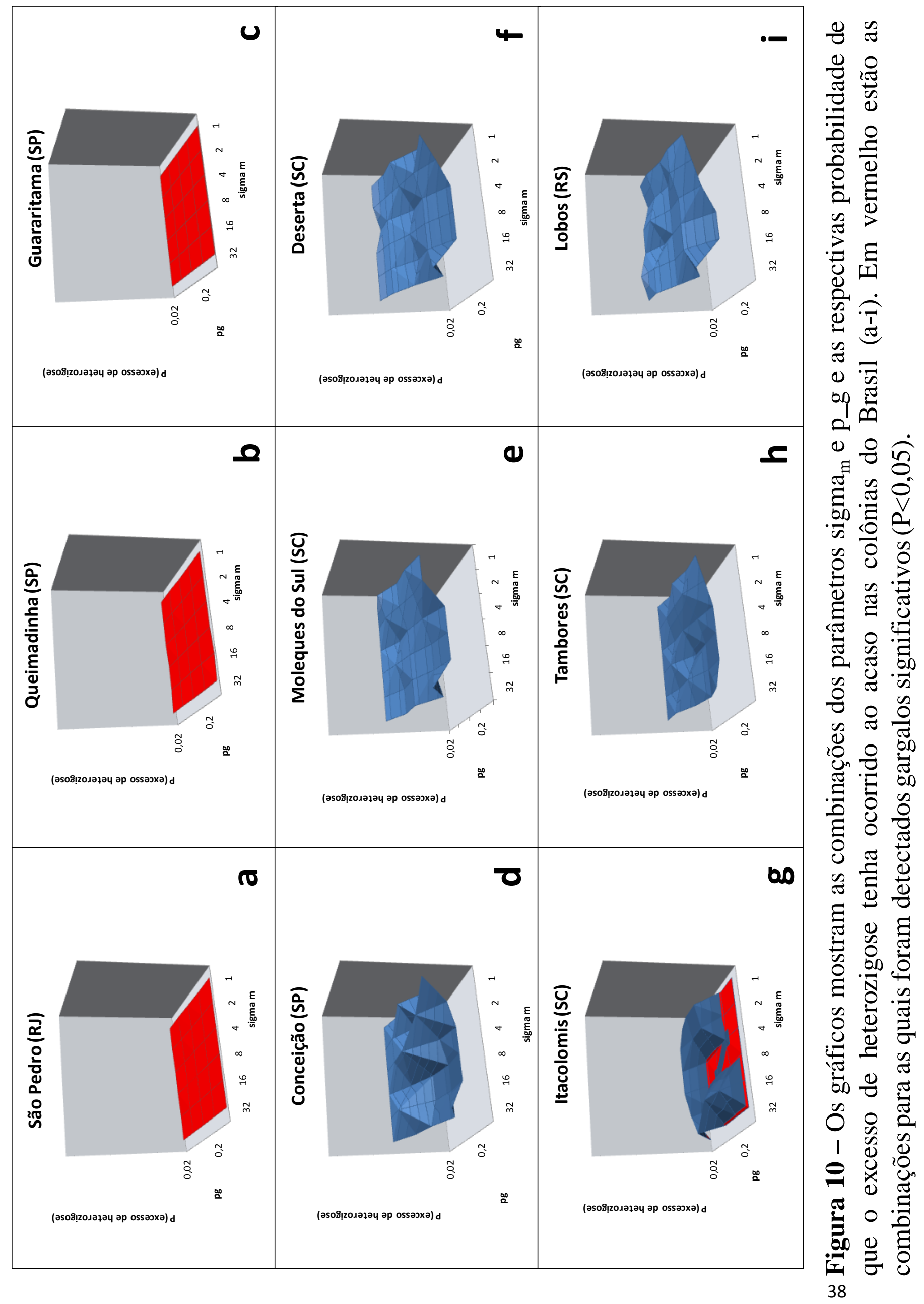




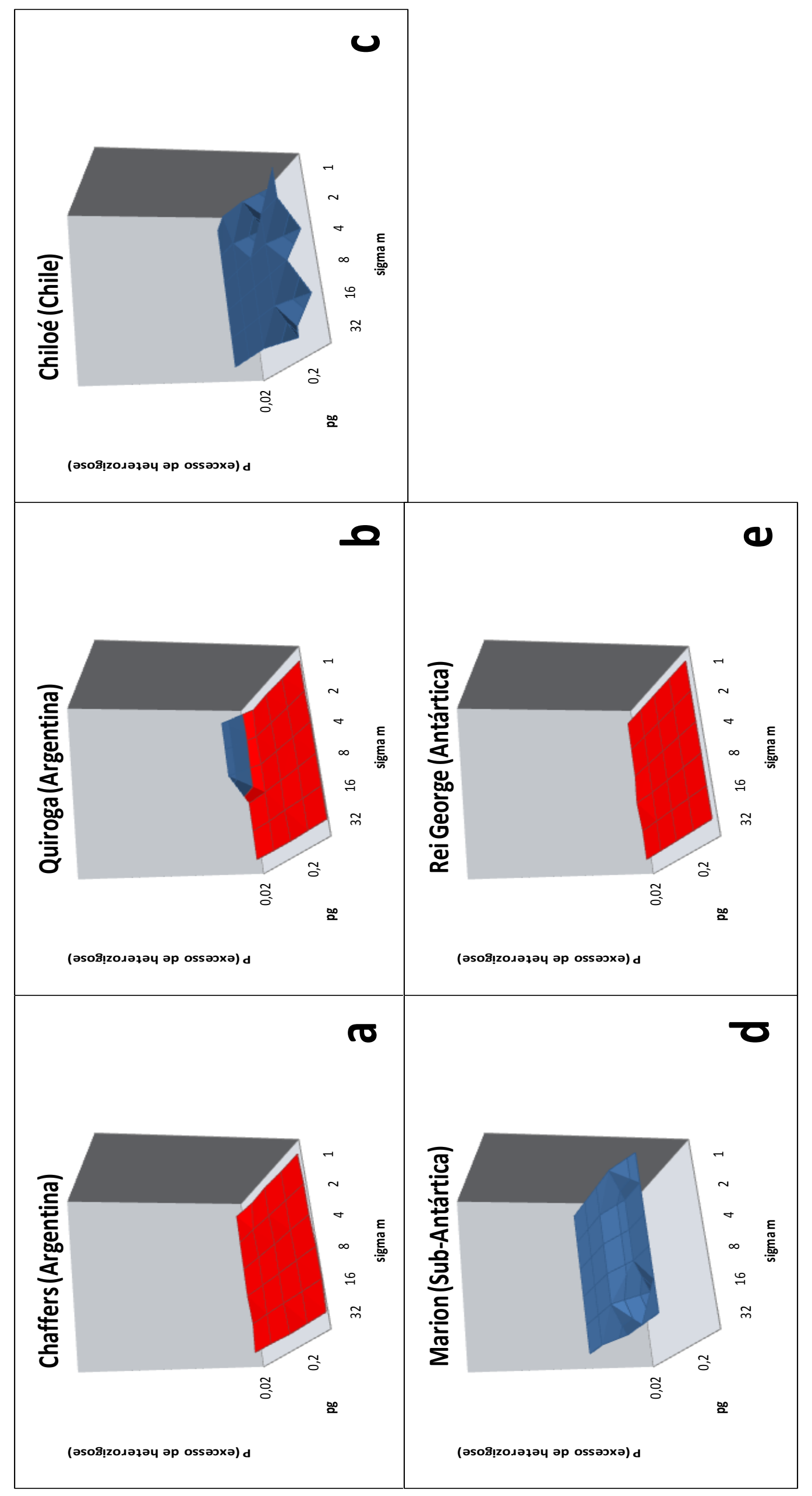

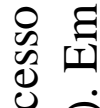

这

$\circ$ ల

ప

它

)

으 0

。

ㅇ

르킄

$\approx \sum^{\pi}$

: 0

¿ิ $\stackrel{0}{0}$

0 0

๘

an 0

일

0 0 อ

त 0

อี ฮ 0

क छ

吃 预

ข

皱

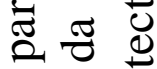

요웜

\&

if $\frac{0}{0}$

疋

클

हี

\&

\& 을

힝 용

\%

छ 융

क 0 .

记

పn

๑ి \&

1.00

$\Rightarrow$ 잉

๑)

照过 


\section{DISCUSSÃO}

\section{Desvios significativos}

Diversas espécies de aves marinhas apresentam forte filopatria, ou seja, retornam para seu local de nascimento ao alcançarem a idade reprodutiva (Friesen et al. 2007). Estudos desse caráter são limitados com L. dominicanus devido à dificuldade de apreensão dos indivíduos adultos, assim, pouco se sabe sobre este aspecto da biologia reprodutiva desta espécie. Os desvios significativos no equilíbrio de Hardy-Weimberg quando os anos de 2001 a 2005 de Guararitama são analisados em conjunto, podem ser decorrentes de uma relação de parentesco entre indivíduos amostrados nos diferentes anos.

Supondo-se que a espécie seja filopátrica, é possível que os indivíduos coletados em anos subseqüentes sejam prole de indivíduos de anos antecedentes, que retornaram ao local para se reproduzir. L. dominicanus atinge a idade reprodutiva aos quatro anos de vida (Sick, 1997). Os anos de coleta estenderam-se de 2001 a 2005. Ao se retirar os indivíduos de 2005 (ano em que os indivíduos de 2001 teriam alcançado a idade reprodutiva), o desvio do equilíbrio de HW deixa de ocorrer, mostrando que, de fato, o desequilíbrio deve ser decorrente da relação de parentesco entre os indivíduos. Este dado contribui para inferir a ocorrência de filopatria em L. dominicanus, embora, para tal conclusão, sejam necessários estudos adicionais, de longo prazo, com métodos de marcação e recaptura e análises de parentesco.

A filopatria é mais forte entre os machos, enquanto as fêmeas apresentam maior capacidade de dispersão, conforme verificado através dos valores diferenciados de $\mathrm{F}_{\mathrm{st}}$. Estudos mostram que a maior parte das espécies de aves filopátricas apresenta maior 
dispersão pelas fêmeas. Os machos geralmente se mantem no território natal para se reproduzirem ou migram para áreas adjacentes, enquanto as fêmeas deixam o território natal em busca de um novo local para reprodução (Greenwoody e Harvey, 1982). Em Larus argentatus, verificou-se que $77 \%$ dos machos retornam para a colônia natal para se reproduzir, enquanto esta taxa é de 54\% nas fêmeas (Chabrzyk \& Coulson, 1976) e a mesma tendência é observada em Larus novaehollandiae scopulinus (Mills, 1973). Na grande maioria das aves, a fêmea escolhe o parceiro sexual através do cuidado que ele demonstra em relação aos recursos locais, que indiretamente demonstram o cuidado parental. Este sistema de escolha do parceiro sexual é o provável motivo pelo qual os machos não dispersam tanto quanto as fêmeas. Ao se manterem no território em que nasceram, os machos têm maior familiaridade com o local e os recursos nele presentes, apresentando, assim, maior facilidade em defender e reunir estes recursos e, por consequência, são mais facilmente escolhidos por uma fêmea. Ao migrar para outro local, pode haver perda neste desempenho, dificultando o sucesso reprodutivo (Greenwood, 1980).

Variabilidade genética, estrutura populacional e fluxo gênico

A riqueza alélica e a riqueza de alelos privados se mostraram baixas em todas as populações de L. dominicanus. Esta baixa variabilidade genética é compatível com a que foi observada por Dantas et al. (2010) nos marcadores mitocondriais CytB e ATPase 6 e 8. Baixos valores de riqueza alélica também são observados em outras espécies do gênero Larus, como Larus michaelis lusitanus (Arizaga et al., 2006), Larus occiidentalis (Pickes, 2008) e da família Laridae, como Sternula antillarum (Draheim et al., 2010) e Sterna hirundo (Sruoga et al., 2006). Isto mostra que, a baixa variabilidade 
genética não é exclusiva de L. dominicanus, mas uma característica comum à família à qual pertence.

As colônias da Argentina, quando comparadas com as das demais regiões, apresentaram os mais altos valores de variabilidade genética. O mesmo foi observado em estudos realizados com Sterna hirundinaceae (Faria et al., 2010) que comparavam colônias do Brasil e da Argentina. Neste trabalho, três hipóteses foram levantadas: a) ocorrência de gargalo populacional genético no Brasil; b) fluxo de migrantes de diferentes localidades para a Argentina; c) maior tamanho populacional efetivo das colônias argentinas. As três hipóteses serão discutidas para L. dominicanus neste trabalho.

A ocorrência de gargalo populacional genético pode ser descartada, já que os resultados mostram que há evidências de gargalo em apenas algumas das colônias brasileiras e não para o conjunto de todas elas, havendo ainda sinal de gargalo nas colônias da Argentina, que ainda assim apresentam maior variabilidade genética. Além disso, a variabilidade das colônias argentinas também é maior que a do Chile, da Antártica e de Marion, tornando esta hipótese pouco provável, já que todas estas localidades deveriam ter sofrido gargalo para que a hipótese fosse corroborada, o que de fato não ocorre.

De acordo com a tabela XI, o Brasil apresenta uma alta taxa de migração para a Argentina, no entanto, é a única localidade com fluxo nesta direção. As demais localidades, não apresentam fluxos diferenciados em relação a nenhuma outra. Além disso, os intervalos de confiança do fluxo Brasil-Argentina são amplos, indicando que os dados para cálculo deste fluxo migratório são insuficientes. Portanto, não se pode 
concluir que a alta variabilidade na Argentina seja resultante da grande visitação de outras localidades.

Há poucos estudos em relação às estimativas de tamanho populacional efetivo, no entanto, com base em trabalhos de censo populacional, é possível verificar que o número de pares reprodutivos na Argentina é maior que nas demais localidades. Em 1992, Chaffers e Quiroga apresentavam respectivamente 3270 e 400 pares reprodutivos (Yorio et al., 1998). Entre 1974 e 1977, foram registrados 200 pares reprodutivos em Marion (Williams et al., 1979); em 1988 e 1989 Rei George apresentou 52 e 47 pares (Lsinski, 1993); no Brasil, entre 1996 e 2002, foram registrados 280 pares em Tambores, 76 em Itacolomis, 497 em Deserta, 177 em Moleques do Sul, 680 em Lobos (Branco, 2003) e são estimados 100 pares em Guararitama (Campos, 2004); no Chile, colônias da região central variaram de 50 a 2000 pares reprodutivos entre 1999 e 2003 (Simeone et al., 2003). Desta maneira, é possível que a alta variabilidade genética observada na Argentina esteja relacionada ao maior número de pares reprodutivos nessa região, que podem contribuir para um elevado tamanho populacional efetivo.

Os resultados do AMOVA mostraram uma alta variabilidade dentro das populações. Quando as populações não foram consideradas em grupos, a porcentagem de variabilidade intrapopulacional foi muito semelhante à encontrada por Dantas et al. (2011), utilizando marcadores mitocondriais e o nuclear beta-fibrinogênio. $O$ agrupamento das populações em Brasil, Argentina, Chile, Marion e Antártica mostrou uma variação significativa entre os grupos, evidenciando que tal agrupamento é relevante, sendo ele muito semelhante ao sugerido pelo programa BAPS. A alta variação intrapopulacional é condizente com os resultados do STRUCTURE, a maior parte da variabilidade encontra-se dentro das populações e não entre elas, portanto, há uma baixa 
estruturação populacional, que não pode ser identificada pelo programa. Resultados semelhantes foram observados em estudos com outras aves marinhas, como trinta-réis (Faria et al., 2010), pingüins (Bouzat et al., 2009) e maçarico-rasteirinho (Gonçalves et $a l$. , 2007), que identificaram uma alta variância intrapopulacional, baixa variância interpopulacional, que são o reflexo da baixa estruturação.

Em aves, a dispersão é facilitada pela alta capacidade de vôo, fazendo com que até mesmo grandes distâncias não sejam uma barreira ao fluxo gênico. O fluxo gênico muito alto pode ser impeditivo para que as populações desenvolvam adaptações locais, o que leva uma variação limitada dos genótipos multiloci (Allendorf \& Luikart, 2007). Assim, o alto fluxo gênico e a fraca estruturação genética podem contribuir para a baixa variabilidade genética na espécie, como ocorre em outras aves marinhas. Soma-se a isso o fato de que L. dominicanus é uma espécie de origem recente, seu ancestral comum mais recente foi estimado em cerca de 153.184 anos (Dantas et al., 2011), desta forma, não deve ter havido tempo suficiente para acumular diversidade genética, apresentando a baixa variabilidade relatada.

Embora fraca, a estruturação populacional existe. Os resultados evidenciaram uma correlação positiva e significativa entre a diferenciação genética e as distâncias geográficas, mostrando a ocorrência do isolamento por distância. Apesar destas evidências, L. dominicanus é uma ave marinha com alta capacidade de vôo, com facilidade de cruzar grandes distâncias. A subespécie L. dominicanus vetula foi observada por pesquisadores do Departamento de Ciências Estatísticas da Universidade de Cape Town (África), no intervalo de 4 meses, em dois pontos que distavam $1211 \mathrm{~km}$ entre si (web.uct.ac.za/depts/stats/adu). Observando-se o gráfico de distâncias genéticas e distâncias geográficas, verifica-se que, embora as colônias da América do Sul estejam 
mais próximas geograficamente da Antártica do que de Marion, a diferenciação genética é menor em relação a esta última e as taxas de migração com destino a Marion são maiores que em direção à Antártica. Assim, deve haver outras barreiras, que não somente a distância geográfica, contribuindo para a estruturação populacional genética em L. dominicanus.

Os padrões de migração nas aves são determinados pela necessidade de encontrar comida, por isso, os oceanos e os ventos desempenham um papel essencial como determinantes destes padrões (Elphick, 2007). Ao longo da rota migratória, as aves precisam forragear, e utilizam o vento de maneira que o forrageamento seja realizado sem o comprometimento do voo (Spear \& Ainley, 2008). Durante a migração, estruturas oceânicas podem oferecer uma boa orientação para a navegação. Nos oceanos do Sul, por exemplo, os pingüins utilizam os gradientes de temperatura das correntes subtropical, subantártica e antártica (Bonadonna et al., 2003).

A ilha Marion está localizada em uma região em que as águas quentes dos oceanos Atlântico, Pacífico e Índico se encontram com as águas geladas dos mares Antárticos, levando à formação da Convergência Antártica (Fig. 12). O encontro destas águas provoca a movimentação de nutrientes depositados no fundo dos oceanos (Capozoli, 1991), estes nutrientes podem desencadear uma alta produtividade da micro e da macrobiota ao longo de toda a linha da Convergência Antártica. É possível que os indivíduos que partem em migração da América do Sul sigam esta linha da Convergência Antártica, que ao mesmo tempo serve como uma boa referência ao longo da navegação, por conta da temperatura oceânica que se reflete na temperatura dos ventos, assim como uma rica fonte de alimentação ao longo do processo migratório. $\mathrm{O}$ arquipélago do Príncipe Eduardo, onde está localizada a ilha Marion, é o segundo grupo 
de ilhas com maior número de espécies que estabelecem colônias reprodutivas no local (Williams et al., 1979), portanto, deve ser uma localidade de grande visitação de diversas aves para forrageamento.

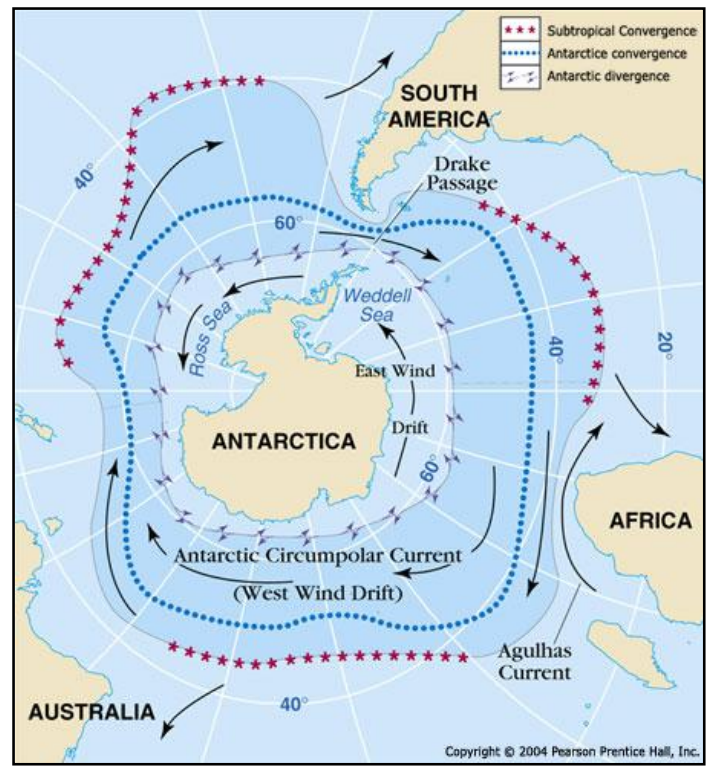

Fig. 12 - Representação no mapa das convergências Antártica e Subantártica. (Ilustração obtida no site polardiscovery.whoi.edu, em 01/11/11).

Em contrapartida às condições que favorecem uma maior migração de indivíduos para Marion do que para a Antártica, há ainda condições que dificultam a migração para esta última localidade. A Antártica é um continente livre de barreiras orográficas, situado no pólo, condições que favorecem a formação de ciclones extratropicais. A energia térmica que chega à Antártica a partir dos continentes encontra nos ciclones uma barreira e é convertida em energia cinética, formando fortes ventos (Felicio, 2007). Estes fortes ventos que se formam ao redor do continente antártico devem atuar como uma barreira que dificulta a entrada das aves migratórias que utilizam os ventos para planar. Assim, a baixa taxa de migração de L. dominicanus para a Antártica deve ser decorrente principalmente de uma barreira física e não da distância 
geográfica. A Tabela XI mostra taxas de migração muito baixas em direção à Antártica e a Figura 9 mostra a presença de indivíduos migrantes desta localidade no Brasil e na Argentina, mas nenhum indivíduo migrante é observado entre os indivíduos da Antártica. Os ventos podem dificultar a entrada de indivíduos no continente, mas, de alguma maneira, devem oferecer uma menor barreira para a imigração.

As grandes distâncias entre a América do Sul, Antártica e Marion por si só não são suficientes para explicar a estruturação populacional entre as colônias destas localidades. Da mesma maneira, é provável que, dentro da América do Sul, a distância também não seja o único determinante. Jouventin (2006), em um estudo com pingüins Eudyptes chrysocome moseleyi e Eudyptes chrysocome chrysocome, mostrou que a diferenciação entre estas sub-espécies é decorrente das temperaturas das águas oceânicas em suas regiões de ocorrência. A primeira sub-espécie ocorre em ilhas subtropicais, enquanto a segunda ocorre em ilhas subantárticas. A diferença de temperatura das águas pode chegar a até $10{ }^{\circ} \mathrm{C}$ e o período reprodutivo pode se iniciar até dois meses mais tarde nos pingüins subantárticos (Warham, 1972 apud Jouventin, 2006).

As colônias de L. dominicanus da Argentina e do Chile se encontram em região subantártica, enquanto as colônias do Brasil estão em região subtropical. No Brasil, o período reprodutivo se inicia em junho e se estende até novembro (Dantas et al., 2010), na Argentina e no Chile, este período vai de novembro a janeiro (Borboroglu e Yorio, 2004). A reprodução de $L$. dominicanus pode não estar diretamente associada à temperatura da água como ocorre com os pingüins, mas indiretamente, uma vez que a temperatura das águas influencia a produtividade de alimento para a espécie e a disponibilidade deste determina os períodos de reprodução. A Figura 8 mostra o 
agrupamento de Chile e Argentina e uma separação destes em relação ao Brasil, esta estruturação deve estar associada às temperaturas das águas que banham as áreas costeiras destes países. Uma maior amostragem de colônias do Chile se faz necessária para que se possa verificar a existência de estruturação entre Chile e Argentina.

Entre as colônias da costa brasileira, nenhuma estruturação foi observada através do programa $B A P S$, no entanto, valores de $\mathrm{F}_{\mathrm{st}}$ se apresentaram significativos para alguns pares de colônias. Uma vez que não existem barreiras físicas e a distância entre as colônias é pequena, a estruturação entre colônias da costa brasileira poderia estar associada a: a) ausência de migração das colônias em períodos não reprodutivos, mantendo-se sempre próximas aos locais de reprodução (Friesen, 2007); b) retorno dos indivíduos sexualmente maduros, em período reprodutivo, para as colônias em que nasceram (filopatria).

A primeira hipótese é descartada, uma vez que há registros no Brasil de ilhas utilizadas por L. dominicanus apenas para forrageamento e não para reprodução (Barbieri, 2008). Estes registros são reforçados por trabalhos da Argentina que registram o forrageamento em ilhas diferentes das de reprodução (Giaccardi, 1997). Portanto, após o período reprodutivo, a espécie dispersa para forragear.

Considerando que diversas espécies de aves marinhas retornam ao local em que nasceram para se reproduzir e que os demais fatores de isolamento entre as colônias brasileiras estão excluídos, é provável que a diferenciação ocorra devido à filopatria. Conforme será discutido adiante, as colônias da costa brasileira apresentam um padrão de gargalo indicativo de efeito fundador. Neste caso, é muito provável que o relatado aumento demográfico esteja levando à necessidade de expansão territorial. Um pequeno grupo de migrantes parte para fundar uma nova colônia, que uma vez estabelecida 
tenderá a se expandir. Esta expansão da espécie e das populações pode ser vista nos dados de marcadores nucleares (Dantas, comunicação pessoal). A alteração do tamanho populacional provoca o desequilíbrio genético entre deriva e mutação, fazendo com que a estruturação não reflita as reais taxas de fluxo gênico (Beaumont \& Balding, 2004). Em populações em desequilíbrio genético, a ausência de estruturação pode ser resultante de diferenciação recente (Withlock \& McCauley, 1998). Desta maneira, na costa brasileira, as populações guardam semelhanças com a população ancestral porque não tiveram tempo suficiente para diferenciar. Se esta hipótese for verdadeira, a nova colônia guardará semelhanças com aquela a partir da qual se originou, até que o fluxo gênico limitado, talvez por filopatria, leve à diferenciação, a qual poderá ser identificada assim que alcançado o equilíbrio genético entre deriva e mutação.

\section{Gargalo populacional}

Todas as colônias brasileiras que apresentaram sinal de gargalo populacional encontram-se no extremo norte da distribuição da espécie na América Latina. Isso leva a concluir que o gargalo observado nestas populações é resultado de efeitos fundadores. O crescimento acelerado da espécie leva à restrição de recursos alimentares e reprodutivos locais, surgindo uma necessidade de buscar novos habitats. A nova população fundada por um grupo de indivíduos leva à perda de variabilidade genética, já que corresponde a um severo gargalo populacional (Luikart et al., 2007). Os gargalos observados apenas nas populações localizadas mais ao norte levam a crer que a ocupação da costa tem ocorrido neste sentido. 
O gargalo populacional observado na colônia de Rei George, na Antártica, pode ser decorrente de: a) extremo da distribuição da espécie ao sul, sendo resultado de uma colonização recente; b) efeito fundador da colônia amostrada; c) efeitos da última glaciação do Pleistoceno. Os estudos realizados até o momento com L. dominicanus ainda não permitem inferir o padrão de colonização desta espécie. Por isso, não é possível afirmar que a Antártica tenha sido colonizada recentemente e o gargalo seja resultante do extremo da distribuição ao sul. Uma única colônia foi amostrada na ilha de Rei George. É possível que esta colônia seja recém estabelecida e o gargalo corresponda a um efeito fundador. Por último, estudos mostram que a última glaciação aumentou tanto a espessura como a extensão de gelo da Antártica, com evidências de que as estruturas de gelo drenaram grande parte da água da região, inclusive de latitudes mais baixas do continente (Canals, 2000). Isso leva a crer que o gargalo possa ser fruto da restrição de habitats na região da Antártica para L. dominicanus no período da última glaciação. Outras espécies de aves marinhas, como o petrel antártico (Pagodroma nívea) também podem ter sofrido os efeitos da última glaciação sobre o continente Antártico (Jouventin, 1985). Uma vez que as três hipóteses são viáveis, seriam necessárias amostragens de outras colônias da Antártica para melhor se compreender as causas do gargalo observado.

A combinação de parâmetros que não levou à detecção de gargalo significativo em Quiroga pode decorrer de dois motivos: a) os baixos valores de sigma ${ }_{m}$ e p_g são os mais próximos dos valores reais para esta população e todos os demais são superestimados, indicando um falso gargalo; b) estes valores estão subestimados, fazendo com que o gargalo não seja detectado. Uma vez que as colônias de Quiroga e Chaffers estão muito próximas entre si e não apresentam diferenciação significativa, 
elas provavelmente estão sob os mesmos efeitos demográficos. Como Chaffers apresentou gargalo significativo para todas as combinações, as combinações de Quiroga que não indicaram gargalo significativo devem ser resultado de uma subestimativa.

A última glaciação também pode ter resultado no gargalo que se observa nas colônias da Argentina. As ilhas Chaffers e Quiroga estão localizadas em uma região de ria, a ria Deseado (Isla et al., 2004). As rias se formam pela inundação de vales de rios com a elevação do nível do mar em períodos interglaciais (Miranda et al., 2002). Desta forma, as ilhas Chaffers e Quiroga devem ter sofrido fortes alterações com a retração do mar durante o período glacial e, da mesma maneira que na ilha Rei George, a disponibilidade de habitats pode ter se tornado restrita. Apesar do sinal de gargalo, as colônias da Argentina apresentaram as maiores variabilidades genéticas entre todas as colônias amostradas, conforme já relatado. É possível que o gargalo tenha ocorrido em populações de tamanho efetivo muito grande, assim, mesmo com a redução populacional, a variabilidade ainda se manteve relativamente alta.

\section{Considerações finais}

Diferentes forças atuam para determinar a estruturação populacional genética de L. dominicanus, sendo elas: isolamento por distância, barreiras físicas e filopatria. A estruturação é aparentemente fraca, mas esta baixa diferenciação pode ser o reflexo de uma diferenciação recente. Os gargalos resultantes de efeito fundador na costa brasileira mostram que a espécie tem ampliado sua área de distribuição.

A relatada expansão populacional de L. dominicanus, assim como de outras espécies de gaivotas, levam à necessidade de implantação de planos de manejo. Em 
outros países o controle populacional de gaivotas já vem sendo realizado há anos com a utilização de diferentes métodos, que podem ser agrupados em: eliminação das aves, utilização de recursos para assustar as aves, remoção dos ovos, esterilização dos ovos e modificação do ambiente em que as gaivotas vivem (Thomas, 1972).

No Brasil, de acordo com a Lei Federal 9.605/98, é proibido “matar, perseguir, caçar, apanhar, utilizar espécimes da fauna silvestre, nativos ou em rota migratória, sem a devida permissão, licença ou autorização da autoridade competente, ou em desacordo com a obtida". Segundo esta mesma lei, "são espécimes da fauna silvestre todos aqueles pertencentes às espécies nativas, migratórias e quaisquer outras, aquáticas ou terrestres, que tenham toda ou parte de seu ciclo de vida ocorrendo dentro dos limites do território brasileiro, ou águas jurisdicionais brasileiras”. A espécie L. dominicanus, portanto, é protegida por lei em território brasileiro, não sendo permitida sua eliminação direta.

As medidas de controle através dos ovos tem se mostrado efetiva para gaivotas, apesar das limitações no caso de colônias de difícil acesso. Estas medidas devem ser realizadas ao longo de anos (Thomas, 1972). A implantação deste método de controle em L. dominicanus poderia contribuir para o controle populacional, mas deveriam ser guardadas as devidas precauções para que não houvesse perda da variabilidade genética. Uma vez que as colônias ainda se encontram em diferenciação e que o habitat de cada colônia pode levar a adaptações locais que contribuem para a variabilidade da espécie, seria interessante que o controle fosse realizado de maneira moderada em diversas colônias e não intensamente em colônias específicas. Inicialmente, as colônias brasileiras com sinal de gargalo poderiam não sofrer este método de controle, mas deveriam ser acompanhadas ao longo dos anos, observando-se a expansão destas populações recém-estabelecidas. Embora as colônias argentinas também tenham 
passado por gargalo, seria interessante que o controle populacional também fosse realizado nestas colônias, que apresentam altos números de pares reprodutivos e, apesar do gargalo, apresentam alta variabilidade genética.

Além de um método direto de controle demográfico, paralelamente devem ser adotadas medidas de manejo do meio ambiente, com educação ambiental das populações locais, para redução da disponibilidade de recursos que servem de alimentação às gaivotas e que são resultantes da ação antrópica. Para este caso, qualquer método de controle populacional se torna apenas paliativo se nenhuma medida ambiental for adotada.

Há registros de construção de ninhos e reprodução de L. dominicanus em áreas urbanas (Branco, 2008). Provavelmente, se métodos de controle populacional e principalmente de manejo ambiental não forem adotados, é possível que a espécie, futuramente, venha a se tornar um grande incômodo em cidades litorâneas, podendo até mesmo vir a constituir um novo animal sinantrópico, como atualmente ocorre com os pombos nas grandes cidades. No entanto, apesar da expansão, a espécie apresenta baixa variabilidade e a elaboração destes planos deve considerar os estudos genéticos, para que a variação entre as localidades sejam preservadas e o futuro da espécie não seja ameaçado. 


\section{BIBLIOGRAFIA}

Allendorf, W.A.; Luikart, G.H. (2007) Conservation and the Genetics of Populations. Blackwell Publishing, Malden, Massachussets.

Amaral, A.C.Z.; Jablonski, S. (2005) Conservação da biodiversidade marinha e costeira no Brasil. Megadiversidade 1: 43-51.

Anderson, J.G.T.; Devlin, C.M. (1999). Restoration of a multi-species seabird colony. Biological Conservation 90: 175-181.

Arizaga, J.; Alda, F.; Doadrio, F.; Herrero, A. (2006) Análisis de la dispersión de la Gaviota Patiamarilla (Larus michahellis lusitanius) en Gipuzkoa. Sociedad de Ciencias Aranzadi.

Bachtrog, D.; Agis, M.; Imhof, M.; Schlötterer, C. (2000) Microsatellite variability differs between dinucleotide repeat motifs-evidence from Drosophila melanogaster. Molecular Biology Evolution 17: 1277-1285

Barbieri, E. (2008) Variação sazonal do gaivotão (Larus dominicanus) durante o ano de 2005 no estuário de Cananéia-Iguape-Ilha Comprida, São Paulo. Biota Neotropical 8: www.biotaneotropica.org.br/v8n2/pt/abstract?article+bn01708022008.

Beaumont, M.A.; Balding, D.J. (2004) Identifying adaptive genetic divergence among populations from genome scans. Molecular Ecology 13: 969-980.

Bonadonna, F.; Benhamou, S.; Jouventin, P. (2003). Orientation in "featureless" environments: the extreme case of pelagic birds. In Avian Migration (ed. P. Berthold, E. Gwinner and E Soneschein), pp 367-377. Berlin Heidelberg: Springer.

Borboroglu, P.G.; Yorio, P. (2004) Habitat requirements and selection by Kelp Gulls (Larus dominicanus) in central and northern Patagonia, Argentina. The Auk 121 (1): 243-252. 
Boswall, J. (1973) Supplementary notes on the birds of Point Tombo, Argentina. Bull. Br. Orn. Club 93: 33-36.

Bouzat, J.L.; Brian, G.W.; Boersma, P.D. (2009) Regional Genetic Structure in the Magellanic Penguin (Spheniscus magellanicus) Suggests Metapopulation Dynamics. The Auk 126 (2): 326-334.

Branco, J.O. (2003) Reprodução de aves marinhas nas Ilhas costeiras de Santa Catarina, Brasil. Revista Brasileira de Zoologia 20 (4): 619-623.

Branco, J.O.; Azevedo, S.M.; Achutti, M.R.N.G. (2008) Reprodução de Larus dominicanus (Aves, Laridae) em ambiente urbano. Revista Brasileira de Ornitologia 16 (3): 240-242.

Brooke, R.K.; Cooper, J. (1979) What is the feeding niche of the Kelp Gull in South Africa? Cormorant 7: 27-29.

Campos, F.P.; Paludo, D.; Faria, P.J.; Martusceli, P. (2004) Aves insulares, residentes ou migratórias das ilhas costeiras do Estado de São Paulo. In: Branco JO (ed) Aves marinhas e insulares brasileiras: bioecologia e conservação. Univali, Itajaí.

Canals, M.; Urgeles, R.; Calafat, A.M. (2000) Deep sea-floor evidence of past ice streams off the Antarctic Peninsula. Geology 28: 32-34.

Capozoli, U. (1991) Antártida: a última terra. Editora da Universidade de São Paulo, São Paulo.

Chabrzyk, G.; Coulson, J.C. (1976). Survival and recruitment in the herring gull Larus argentatus. Journal Animal Ecology 45: 187-203.

Corander, J.; Marttinen, P.; Sirén, J.; Tang, J. (2008) Enhanced Bayesian modeling in BAPS software for learning genetic structures of populations. BMC Bioinformatics 9: 539. 
Crochet, P.A.; Chen, J.J.Z.; Pons, J.M. (2003) Genetic differentiation at nuclear and mitochondrial loci among large white-headed gulls: sex-biased interspecific gene flow? Evolution 57: 2865-2878.

Dakin, E.E.; Avise, J.C. (2004) Microsatellite null alleles in parentage analysis. Heredity 93: 504-509.

Dantas, G.P.M., Godinho, R.; Morgante, J.S.; Ferrand, N. (2010) Development of new nuclear markers and characterization of single nucleotide polymorphisms in kelp gull (Larus dominicanus). Molecular Ecology Resources 9 (4): 1159-1161.

Dantas, G.P.M.; Meyer, D.; Godinho, R.; Ferrand, N.; Morgante, J.S. (2011) Genetic variability in mithocondrial and nuclear genes to understand the evolutionary history in Kelp Gull. Journal of Avian Biology (in press).

del Hoyo, J.; Elliott, A.; Sargatel, J. (Eds) (1996) Handbook of the birds of the world. Vol. 3. Hoatzin to auks, Barcelona, Lynx Ediciones.

Draheim, H.M.; Miller, M.P.; Baird, P.; Haig, S.M. (2010) Subspecific Status and Population Genetic Structure of Least Terns (Sternula antillarum) Inferred by Mitochondrial DNA Control-Region Sequences and Microsatellite DNA. The Auk 127 (4): 807-819.

Ellegren, H. (2004) Microsatellites: simple sequences with complex evolution. Nature Reviews 5: 435-445.

Elphick, J. (1995) The Atlas of Bird Migration. Random House, New York.

Evanno, G.; Regnaut, S.; Goudet, J. (2005) Detecting the number of clusters of individuals using the software structure: a simulation study. Molecular Ecology 14: 2611-2620.

Excoffier, L.; Smouse, P.E.; Quattro, J.M. (1992) Analysis of molecular variance inferred from metric distances among DNA haplotypes: application to human mitochondrial DNA restriction data. Genetics 131: 479 - 91. 
Excoffier, L.; Laval, G.; Schneider, S. (2005) Arlequim (version 3.0): An integrated software package for population genetics data analysis. Evol. Bioinform Online 1: 47-50.

Faria, P.J.; Capos, F.P.; Branco, J.O.; Musso, M.C.; Morgante, J.S.; Bruford, M.W. (2010) Journal Avian Biology 41: 378-387.

Felicio, R. «Antártida », Confins [En ligne], 1 | 2007, mis en ligne le 11 juin 2007, consulté le 12 novembre 2011. URL: http://confins.revues.org/122; DOI : $10.4000 /$ confins. 122

Fordham, R.A. (1970) Mortality and population change of Dominican Gulls in Wellington, New Zealand. Journal Animal Ecology 39: 13-27.

Frere, E.; Gandini, P.A.; Boersma, P.D. (1992) Effects of nest type and location on reproductive success of the Magellanic Penguin Spheniscus magellanicus. Marine Ornithology 20: 1-6.

Friesen, V.L.; Burg, T.M.; McCoy, K.D. (2007) Mechanisms of population differentiation in seabirds. Molecular Ecology 16: 1765-1785.

Giaccardi, M.; Yorio, P.; Lizurume, E. (1997) Patrones estacionales de la gaviota cocinera (Larus dominicanus) en un basural Patagónico y sus relaciones con el manejo de residuos urbanos y pesqueros. Ornitologia Neotropical 8 (2): 77-84.

Given, A.D.; Mills, J.A.; Baker, A.J. (2002) Isolation of polymorphic microsatellite loci from thered-billed gull (Larus novaehollandiae scopulinus) and amplification in related species. Molecular Ecology 2: 416-418.

Gochfeld, M. (1980) Timing of breeding and chick mortality in central and peripheral nests of Magellanic Penguins. Auk 97: 191-193. 
Gonçalves, E.C.; Rodrigues, A.A.F.; Ferrari, S.F.; Silva, A.; Schneider, M.P.C. (2007) Molecular evolution of $\beta$-fibrinogen intron 7 applied to the population genetics of the Semipalmated Sandpiper (Calidris pusilla) on the northern Coast of Brazil. Revista Brasileira de Ornitologia 15 (2): 253-260.

Greenwood, P.J. (1980) Mating systems, philopatry and dispersal in birds and mammals. Animal Behaviour 28: 1140-1162.

Greenwoody, P.J.; Harvey, P.H. (1982) The natal and breeding dispersal of birds. Annual Review of Ecology and Systematics 13: 1-21.

Griffths, R.; Double, M.C.; Orr, K.; Dawson, R. (1998) A DNA test to sex most birds. Molecular Ecology 7: 1071-1075.

Hamilton, M.B. (2009) Population Genetics. Willey Blackwell, Oxford.

Higgins, K.; Lynch, M. (2001) Metapopulation extinction caused by mutation accumulation. Proceedings of the National Academy of Sciences of the USA 98: 2928-2933.

Hoelzel, R.; Hoelzel, A.R. (1998) Molecular Genetic Analysis of Populations: A Practical Approach. Ed. Oxford University Press, Oxford, EUA.

Humphrey, P.S.; Bridge, D.; Reynolds, P.D.; Peterson, R.T. (1970) Birds of Isla Grande (Tierra del Fuego). Washington, D.C., Smithsonian Institution.

Isla, F.; Iantanos, N.; Estrada, E. (2004) Subtidal dynamics and environmental conditions of the Río Deseado estuary, Santa Cruz. Revista de la Asociación Geológica da Argentina 59 (3): 367-375.

Jouventin, P.; Cuthbert, R.J.; Ottvall, R. (2006) Genetic isolation and divergence in sexual traits: evidence for the northern rockhopper penguin Eudyptes moseleyi being a sibling species. Molecular Ecology 15: 3413-3423. 
Jouventin, P.; Viot, C.R. (1985) Morphological and genetic variability of snow petrels. The International Journal of Avian Science 127 (4): 430-441.

Kalinowski, S.T. (2004) HP-RARE 1.0: a computer program for performing rarefaction on measures of allelic richness. Molecular Ecology Notes 5 (1): 187-189.

Kumar, S.; Fladung, M. (2004) Molecular Genetics and Breeding of Forest Trees. Ed. Food Products Press, New York, EUA.

Liedloff, A.C. (1999) Mantel Nonparametric Test Calculator. Version 2.0. School of Natural Resource Sciences, Queensland University of Technology, Australia.

Loeschcke, V.; Tomiuk, J.; Jain, S.K. (1994) Conservation Genetics. Birkhäuser Verlag, Basel, Switzerland.

Lsinski, G. (1993) Monitoring of birds and pinnipedians on King George Island (South Shetland Islands) in 1989/1990. Pol. Polar Res. 14: 75-89.

Piry, S.; Luikart, G.; Cornuet, J.M. (2007) Computer note. BOTTLENECK: a computer program for detecting recent reductions in the effective size using allele frequency data. J Hered 90 (4): 502-503.

Mills, J.A. (1973) The influence of age and pair-bond on the breeding biology of the red-billed gull, Larus novaehollandiae scopulinus. Journal Animal Ecology 42: 147163.

Miranda, L.B.; Castro, B.M.; Kjerfve, B. (2002) Princípios de Oceanografia Física de Estuários. Editora da Universidade de São Paulo, São Paulo.

Murphy, R.C. (1936) Oceanic birds of South America. Vol. 2. American Museum of Natural History and Macmillan, New York.

Peakall, R.; Smouse, P. (2005) GENALEX 6: Genetic analysis in Excel. Population genetic software for teaching and research. Molecular Ecology Notes 6 (1): 288-295. 
Pearse, D.E.; Crandall, K.A. (2004) Beyond $F_{\text {ST: }}$ analysis of population genetic data for conservation. Conserv. Genet. 5: 585-602.

Pickes, C. (2008) The effects of ocean climate variability on western gull (Larus occidentalis) ecology and population genetics. ProQuest Dissertations and Theses.

Primmer, C.R.; Ellegren, H. (1998) Patterns of molecular evolution in Avina microsatelites. Molecular Biology Evolution 15 (8): 997-1008.

Pritchard, J.K.; Stephens, M.; Donnelly, P. (2000) Inference of population structure using multilocus genotype data. Genetics 155: 945-959.

Punta, G.; Herrera (1995) Predation by Southern Giant Petrels Macronectes giganteus on adult Imperial Cormorants Phalacrocorax atriceps. Marine Ornithology 23: 166167.

Raymond, M.; Rousset, F. (1995) An exact test for population differentiation. Evolution 49 (66): 1280-1283.

Rowntree, V.J.; McGuinness, P.; Marshall, K..; Payne, R.; Sironi, M.; Seger, J. (1998) Increased harassment of Right Whales (Eubalaena australis) by Kelp Gulls (Larus dominicanus) at Península Valdés, Argentina. Marine Mammal Science 14: 99-115.

Sambrook, K. J.; Russel, D.W.; Sambrook, J. (2001) Molecular Cloning: a Laboratory Mannual. CSHI, New York, USA.

Schlötterer, C.; Pemberton, J. (1994) The use of microsatellites for genetic analysis of natural populations. Pp. 203-214 in B. Schierwater, B. Streit, G. Wagner.

Schreiber, E.A.; Burger, J. (2000) Biology of Marine Birds. CRC Press, London.

Sick, H. (1997) Ornitologia Brasileira. Nova Fronteira, Rio de janeiro, Brasil. 
Simeone, A.; Lara-Jorquera, G.; Bernal, M.; Garthe, S.; Sepúlveda, F.; Villablanca, R.; Ellenberg, U.; Contreras, M.; Muñoz, J.; Pince, T. (2003) Breeding distribution and abundance of seabirds on islands off northcentral Chile. Revista Chilena de História Natural 76 (2): 323-333.

Spear, L.B.; Ainley, D.G. (2008) Flight behaviowr of seabirds in relation to wind direction and wing morphology. The International Journal of Avian Science 139 (2): 221-233.

Sruoga, A.; Butkauskas, D.; Prakas, P.; Paulauskas, A. (2006) Evaluation of the genetic structure of the breeding Common Tern (Sterna hirundo) population by means of microsatellite markers. Biologija 1: 47-52.

Stahl, J.C.; Mougin, J.L. (1986) Le régime alimentaire du goéland dominicain Larus dominicanus de $1^{\prime}$ ile de la Possession, Archipel Crozet $\left(46^{\circ} 25^{\prime} \mathrm{S}, 51^{\circ} 45^{\prime} \mathrm{E}\right)$. Oiseau 56: 287-291.

Steele, W.K. (1992) Diet of Hartlaub's Gull Larus hartlaubii and the Kelp Gull $L$. dominicanus in the southwestern Cape Province, South Africa. Ostrich 63: 68-82.

Thomas, P.O. (1988) Kelp Gulls, Larus dominicanus, are parasites on flesh of the Right Whale, Eubalaena australis. Ethology 79: 89-103.

Thomas, G.J. (1972) A review of gull damage and management methods at nature reserves. Biological Conservation 4 (2): 117-127.

Tirard, C.; Helfenstein, F.; Danchin, E. (2002) Polymorphic microsatellite in the blacklegged kittiwake Rissa tridactyla. Molecular Ecology Notes 2: 431-433.

Waples, R.S.; Gaggiotti, O. (2006) What is a population? An empirical evaluation of some genetic methods for identifying the number of gene pools and their degree of connectivity. Molecular Ecology 15: 1419-1439. 
Williams, A.J.; Siegfried, W.R.; Burger, A.E.; Berruti, A. (1979) The Prince Edward Islands: A sanctuary for seabirds in the Southern Ocean. Biological Conservation 15 (1): $59-71$.

Williamson-Natesan, E.G. (2005) Comparison of two methods for detecting bottlenecks from microsatellite loci. Conservation Genetics 6 (4): 551-562.

Wilson, G.A.; Rannala, B. (2003) Bayesian inference of recent migration rates using multilocus genotypes. Genetics 163 (3): 1177-1191.

Whitlock, M.C.; McCauley, D.E. (1999) Indirect measures of gene flow and migration: FST $^{1} 1 /(4 N m+1)$. Heredity $82: 117-125$.

Yorio, P.; Boersma, P.D. (1994) Consequences of nest desertion and inattendance for Magellanic Penguin hatching success. The Auk 111, 215-218.

Yorio, P.; Quintana, F. (1996) Efectos del disturbio humano sobre una colonia mixta de aves marinas em Patagonia. El Hornero 14: 89-96.

Yorio, P.; Bertellotti, M.; Gandini, P.; Frere, E. (1998) Kelp Gulls Larus dominicanus breeding on the Argentine coast: population status and relationship with coastal management and conservation. Marine Ornithology 26: 11-18. 